\title{
Desigualdad en América Latina: una medición global
}

\author{
Verónica Amarante, Marco Galván y Xavier Mancero
}

RESUMEN

En este artículo se combinan los datos individuales de las encuestas de hogares de los países latinoamericanos para obtener un vector de ingresos regional y analizar su distribución y cambios recientes. Se investiga si en la última década los cambios distributivos en los países han mejorado la distribución de los ingresos entre los individuos, o incrementado las brechas. Los indicadores de desigualdad global de la región muestran una caída significativa durante 2003-2012. Esta merma en la desigualdad global se explica fundamentalmente por la reducción de la desigualdad en los países latinoamericanos. Los ingresos de los habitantes de América Latina son hoy más igualitarios en términos relativos que hace una década, aunque las diferencias en los ingresos promedio de los países son mayores.

PALABRAS CLAVE

CLASIFICACIÓN JEL

AUTORES
Desarrollo económico, desarrollo social, ingresos, distribución del ingreso, igualdad, indicadores socioeconómicos, América Latina

D31, I3, O57

Verónica Amarante es Directora de la Sede de Montevideo, Uruguay, de la Comisión Económica para América Latina y el Caribe (CEPAL). verónica.amarante@cepal.org

Marco Galván es Asistente de Investigación de la División de Estadísticas de la Comisión Económica para América Latina y el Caribe (CEPAL). marco.galvan@cepal.org

Xavier Mancero es Jefe de la Unidad de Estadísticas Sociales de la División de Estadísticas de la Comisión Económica para América Latina y el Caribe (CEPAL).xavier.mancero@cepal.org 


\section{I}

\section{Introducción}

El estudio de la desigualdad ha ocupado un lugar central en las investigaciones sobre los países de América Latina, sobre todo porque desde que existen estadísticas confiables, basadas en microdatos, los países de la región aparecen entre los más desiguales del mundo (véase, por ejemplo, Alvaredo y Gasparini, 2015). Diversos estudios sobre desigualdad en América Latina se han basado en la consideración de las desigualdades en el interior de los países, y se ha conformado así una literatura abundante — reseñada en la sección II de este artículo_ que estudia la desigualdad desde diversas perspectivas e intenta comprender sus determinantes y evolución, focalizándose en el cambio en la tendencia creciente de la desigualdad del ingreso a partir de 2002 en la región.

Sin embargo, una pregunta menos abordada respecto de América Latina se refiere a cuán diferentes son los ingresos de los habitantes de la región, considerada esta globalmente, y cómo ha evolucionado esa desigualdad en la última década, en cuyo transcurso se ha producido una caída en los niveles de desigualdad de la mayoría de los países de la región. En este artículo se procura responder a esa pregunta, que se considera relevante para completar el diagnóstico sobre la evolución reciente de la desigualdad en América Latina. Con miras a ello, se presentan diversos indicadores sobre la evolución del ingreso de los individuos de la región considerada globalmente, y se analiza en particular la evolución de la desigualdad. Se indaga si los cambios distributivos

$\square$ Los autores agradecen a Marcela Gómez por su labor como Asistente de Investigación para la elaboración de este artículo. en el interior de los países de la región durante la última década han estado acompañados de mejoras en la distribución de los ingresos entre los latinoamericanos, o si han implicado incrementos en las brechas. El análisis se basa en la combinación de los datos de las encuestas de hogares de la región, utilizando criterios similares para el tratamiento de los datos de los distintos países, y específicamente para el cómputo del ingreso de los hogares, de manera que el vector resultante sea consistente entre países.

El artículo se organiza de la siguiente manera: luego de la Introducción, en la sección II se presenta una breve revisión de los avances de la literatura en relación con la discusión y medición de la desigualdad global. En la sección III se sintetiza la evolución de la desigualdad en el interior de los distintos países de la región en los últimos años, así como las explicaciones existentes respecto de esta evolución. En la sección IV se presentan los datos utilizados en el artículo y se describen las opciones metodológicas adoptadas para la medición de la desigualdad a nivel regional. Se exponen luego los principales resultados de este trabajo: en la sección $\mathrm{V}$ se discuten las diferencias promedio de ingresos en la región, y en la sección VI se aprecia la evolución de los ingresos de los latinoamericanos y su distribución, comparando la información entre principios del año 2000 (más específicamente de 2003, cuando se produce el cambio de tendencia en la evolución de la desigualdad en la mayoría de los países de la región) y la información más reciente disponible que corresponde a 2012. Finalmente, en la sección VII se plantean los comentarios finales.

\section{II}

\section{La desigualdad global}

La relevancia del estudio de la desigualdad puede argumentarse sobre la base de fundamentos originados en las teorías de la justicia social, y también de aquellos puramente instrumentales vinculados a la eficiencia económica. La preocupación por la desigualdad basada en fundamentos de justicia social no ha estado libre de debate (Feldstein, 1999; Milanovic, 2007, entre otros), y se ha discutido, entre varios temas, si lo verdaderamente preocupante es la desigualdad de oportunidades (tal como propone Roemer, 1998) o la desigualdad de resultados, entre ellos el ingreso. En su reciente publicación, Atkinson (2015) brinda tres razones debido a las cuales 
la economía debe seguir preocupada por la distribución de los resultados, incluido el ingreso. Por una parte, atendiendo a una cuestión moral, no se puede desconocer la situación de los individuos más desaventajados, aun en el caso hipotético en que la igualdad de oportunidades estuviera garantizada ${ }^{1}$. Además, la estructura de precios o retornos finales es tan desigual, que amerita la preocupación por los resultados, y explica también el consenso existente acerca de que se debe garantizar la igualad de oportunidades. Finalmente, la desigualdad de resultados presente afecta a la igualdad de oportunidades de las generaciones futuras. La preocupación por la escasa movilidad social y la necesidad de garantizar la igualdad de oportunidades conducen a la necesidad de reducir la desigualdad de resultados en el presente. Si se consideran los argumentos puramente instrumentales, el debate y la controversia a nivel empírico se centran en el vínculo entre la desigualdad de ingresos y el crecimiento económico, y más concretamente en los potenciales efectos adversos de la desigualdad respecto del crecimiento, a través de diversos canales que incluyen la economía política, el conflicto y las imperfecciones en el mercado de capitales, entre otros (véanse, por ejemplo, Alesina y Rodrik, 1994; Alesina y Perotti, 1996; Persson y Tabellini, 1994; Barro, 2000).

Las razones expuestas explican la importancia del estudio de la desigualdad, que se traduce en una amplia literatura que suele circunscribirse a lo que sucede en un país, o a comparaciones entre países. Sin embargo, una parte de los estudios sobre desigualdad se ha focalizado en el análisis de la desigualdad mundial. Según Milanovic (2005), se pueden distinguir tres conceptos diferentes con los que se ha intentado reflejar la desigualdad a nivel mundial. El primero corresponde a los estudios más antiguos sobre la temática, en que se estimaba la desigualdad mundial considerando el nivel que prevalecería si el mundo estuviera poblado por individuos representativos de cada país, cada uno de ellos con el ingreso promedio correspondiente a su país. Este enfoque se conoce como de desigualdad internacional, y básicamente consiste en una comparación entre ingresos medios de los distintos países, sin ponderar por la población correspondiente a cada uno de ellos. El segundo concepto se refiere también a la desigualdad internacional, pero considera la diferencia de tamaño

\footnotetext{
${ }^{1}$ En palabras de Milanovic (2007), el ingreso de los otros individuos es parte de la función de utilidad de cada persona, y por lo tanto, altos niveles de desigualdad afectan el bienestar individual, aunque reconoce la posibilidad de que los individuos estén motivados por buenos sentimientos (como los sujetos a los que se refiere Atkinson (2015)) o malos sentimientos (por ejemplo, envidia).
}

entre los países, por lo tanto, se trata de un indicador similar al anterior, pero que pondera por la población de cada país. El tercer concepto alude a lo que se entiende por desigualdad global, y recupera al individuo como unidad de análisis, ignorando las fronteras nacionales. Este último es el enfoque aplicado en este trabajo, que procura reflejar las diferencias de ingresos entre los individuos de la región.

En diversos estudios se ha intentado una aproximación a este tercer concepto, que refleja la desigualdad global, derivando la distribución mundial a partir de datos del producto interno bruto (PIB) per cápita e indicadores sintéticos de desigualdad de los países (Schultz, 1998), o combinando información de encuestas de hogares y datos del PIB per cápita (Berry, Bourguignon y Morrison, 1983; Bourguignon y Morrison, 2002; Sala-i-Martin, 2006, entre otros). En otros estudios se ha abordado el examen de la desigualdad global solo sobre la base de información de encuestas de hogares, a partir de las cuales se deriva la distribución mundial de ingresos (Milanovic, 2005).

En trabajos más recientes sobre la desigualdad global en las últimas décadas (Milanovic, 2012; Lakner y Milanovic, 2013; Niño-Zarazúa, Roope y Tarp, 2014; Anand y Segal, 2015) se combina información de las encuestas de hogares y se consideran cuantiles de la distribución del ingreso de cada país (generalmente ventiles), imputando a cada cuantil el ingreso per cápita promedio y construyendo una base de datos que contiene los cuantiles de los distintos países del mundo ${ }^{2}$. Estos trabajos coinciden en señalar que el nivel de desigualdad global es muy elevado, comparable al de los países de mayor desigualdad del mundo, y que presenta variaciones relativamente menores en el tiempo.

En términos de desigualdad regional, Gasparini y otros (2008) reportan que, combinando datos de las encuestas de hogares de la región, se encuentra un patrón similar en la desigualdad global que en la desigualdad en el interior de los países: aumento en los años noventa y caída a partir de los primeros años de la década de $2000^{3}$. Otro antecedente para América Latina es el estudio de Gasparini y Gluzmann (2012), donde se utiliza información de las Encuestas Mundiales Gallup de 2006 que se desarrollaron en 132 países en

\footnotetext{
${ }^{2}$ Los cuantiles son puntos tomados a intervalos regulares de la función de distribución de una variable aleatoria. A modo de ejemplo, cuando la distribución del ingreso se divide en 20 grupos, se denominan ventiles. De este modo, el primer ventil comprende al $20 \%$ de individuos más pobres.

${ }^{3}$ En estas estimaciones se consideran 12 países en el período 1990-2006.
} 
ese año. No obstante que la captación del ingreso en estas encuestas no es tan precisa como en las encuestas de hogares, ellas permiten analizar la desigualdad global. Los autores estiman indicadores de desigualdad por región, y encuentran que el coeficiente de Gini de América Latina es 0,525 en 2006, muy superior al que muestran Europa Occidental $(0,402)$, América del Norte $(0,438)$ y Europa Oriental y Asia Central $(0,497)$. Sin embargo, los niveles de desigualdad de la región latinoamericana son inferiores a los que muestran Asia del Sur $(0,534)$, el Caribe $(0,591)$ y Asia Oriental y Asia y el Pacífico $(0,594)$. Los autores argumentan que América Latina está conformada por países con altos y similares niveles de desigualdad, pero que considerada globalmente la región no es la más desigual del mundo. Si bien los países latinoamericanos son relativamente muy desiguales, la dispersión de ingresos entre ellos es menor que en otras regiones del mundo.

Entre los aspectos que según Anand y Segal (2008) justifican el estudio de la desigualdad global, se destacan los factores morales y también las consecuencias que puede tener la desigualdad global. En relación con el primer aspecto, las disparidades entre los ingresos individuales a nivel global pueden ser consideradas injustas, y esto amerita analizar qué tan diferente es el ingreso de los individuos considerados globalmente y no en función de su nacionalidad ${ }^{4}$. Por otra parte, la evidencia respecto de la desigualdad a nivel mundial resulta interesante para analizar el poder predictivo de las teorías: de acuerdo con la teoría de crecimiento neoclásica se debería observar

\footnotetext{
${ }^{4}$ En esta línea, Milanovic (2015) señala que, al nacer en un determinado país, las personas reciben dos "bienes públicos": el ingreso promedio del país y la desigualdad en su distribución. Más de la mitad de la variabilidad del ingreso global se explica por las circunstancias de nacimiento, entre ellas el ingreso medio y la desigualdad del ingreso en el país de nacimiento.
}

una convergencia de ingresos entre los países, e incluso entre los individuos, en el largo plazo, mientras que en la teoría de la dependencia se predice divergencia.

Los estudios sobre desigualdad global han estado básicamente motivados por la necesidad de evaluar en qué medida - aun cuando la globalización hubiera implicado aumentos en la desigualdad en el interior de los países- podría también haber implicado descensos en la desigualdad global. Esto querría decir que las diferencias entre los individuos del mundo serían menores, y podría ser resultado de que los países más pobres (y poblados) hubieran crecido más rápido que los más ricos (y menos poblados). En estos estudios también se procura analizar si las reglas que gobiernan las interacciones entre países ricos y pobres inciden en la desigualdad global. A medida que existe mayor integración entre los países, también aumenta la movilidad de factores entre fronteras, así como la influencia de las condiciones de vida de la población de otros países en las percepciones y aspiraciones de la población de un cierto país. Todos estos aspectos hacen que la desigualdad se torne relevante más allá de las fronteras nacionales.

En el caso del análisis de la desigualdad global considerando a los países de América Latina, el interés no reside en la vinculación entre las consecuencias de la globalización y la desigualdad, como cuando se considera al mundo en su conjunto, ya que la mayor parte de los flujos comerciales y financieros no se producen dentro de la región, sino entre la región y el mundo, y podrían estar afectando a todos los países de manera similar. El principal interés radica en la comprensión de la situación relativa de los individuos de la región, así como en la comprobación de la medida en que el reciente descenso de la desigualdad del ingreso en la mayor parte de los países de la región se ha dado conjuntamente con una convergencia o divergencia en el bienestar de los individuos a nivel regional.

\section{III}

\section{Evolución reciente de la desigualdad en los países de América Latina}

En los últimos 10 años se ha producido un cambio relevante en los indicadores de desigualdad del ingreso de América Latina. A partir de 2002 o 2003 (según el país), en la mayoría de los países de la región comienza a evidenciarse un descenso en los niveles de desigualdad del ingreso. Los cambios han ocurrido de manera gradual y son apenas perceptibles en las variaciones interanuales, pero resultan evidentes al comparar períodos más 
largos. Si se considera el período 2002-2012, en 16 de los 17 países comprendidos en este estudio se observan mejoras distributivas, reflejadas en la disminución del coeficiente de Gini (véase el gráfico 1). La excepción la constituye Costa Rica, cuyo coeficiente de Gini supera en 2012 el valor de 2002. Esta reciente tendencia a la baja es estadísticamente significativa y tuvo lugar en un contexto de crecimiento económico sostenido y reducción de la pobreza en la región. La tendencia a la caída de la desigualdad ha sido más pronunciada a partir de 2008 (CEPAL, 2013).

Los cambios registrados a partir del descenso en el coeficiente de Gini se reflejan también en la evolución de la participación en los ingresos totales de los quintiles extremos $^{5}$. En la mayoría de los países (con excepción de la República Dominicana, el Paraguay y Honduras), la participación del quintil más pobre en los ingresos totales se ha incrementado entre 2002 y 2012 (véase el gráfico 2). En el otro extremo, la participación del quintil más rico se ha reducido en casi todos los países (excepto en el Paraguay) (véase el gráfico 3). Los datos más recientes disponibles indican que el quintil más pobre (es decir, el 20\% de los hogares con menores ingresos) capta en promedio un 5\% de los ingresos totales, con participaciones que varían entre menos del $4 \%$ (en Honduras, el Paraguay y la República Dominicana) y el 10\% (en el Uruguay), mientras que la participación

${ }^{5}$ Las cifras citadas sobre la participación de los quintiles se refieren a quintiles de hogares ordenados en función de su ingreso por persona. en los ingresos totales del quintil más rico promedia el $47 \%$, con un rango que va del $35 \%$ (en el Uruguay) al $55 \%$ (en el Brasil) (CEPAL, 2013).

Este cambio en la tendencia de la desigualdad del ingreso ha sido objeto de diversas interpretaciones. Los ingresos laborales, la principal fuente de recursos de los hogares, han sido el factor determinante en este descenso de la desigualdad. En efecto, más allá de las repercusiones positivas derivadas de incrementos en el empleo, de caídas en la tasa de dependencia y de transferencias monetarias redistributivas, el factor que explica la mayor parte del retroceso de la desigualdad de ingresos es la reducción en el diferencial salarial entre trabajadores calificados y no calificados (CEPAL, 2012).

El descenso en la prima por calificación, que se expresa en la reducción de los diferenciales en relación con el grupo sin educación, muestra un patrón claro y consistente entre países (véase el gráfico 4). A su vez, conjuntamente se produce un aumento en los niveles educativos de la población (y de los ocupados). Sin embargo, resulta difícil comprender si la evolución de este diferencial salarial obedece sobre todo a cambios en la demanda relativa de trabajadores calificados o a cambios en su oferta relativa. Mientras algunos autores han subrayado la importancia del incremento en la oferta relativa de trabajadores calificados (López-Calva y Lustig, 2010; Azevedo y otros, 2013), otros han enfatizado el posible papel del aumento de la demanda relativa de trabajadores no calificados, en un contexto de incremento de la mano de obra calificada (Gasparini y otros, 2012; De la Torre, Messina y Pienknagura, 2012).

GRÁFICO 1

América Latina (18 países): coeficiente de Gini, alrededor de 2002 y 2012

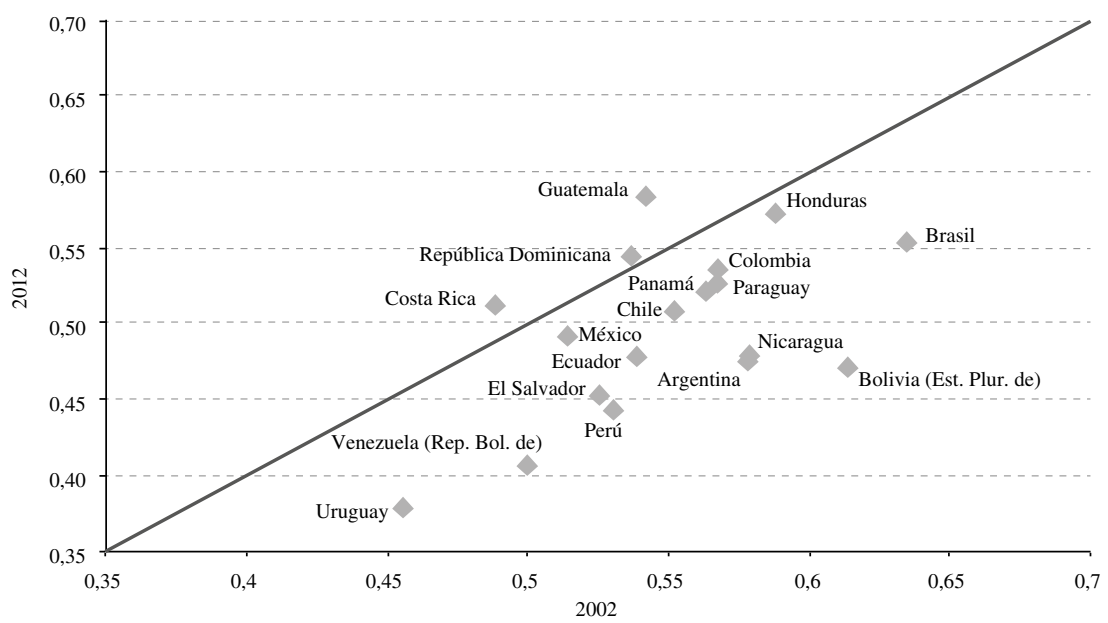

Fuente: Elaboración propia sobre la base de CEPALSTAT. 
GRÁFICO 2

América Latina (17 países): participación en los ingresos totales del quintil más pobre, alrededor de 2002 y 2012

(En porcentajes)

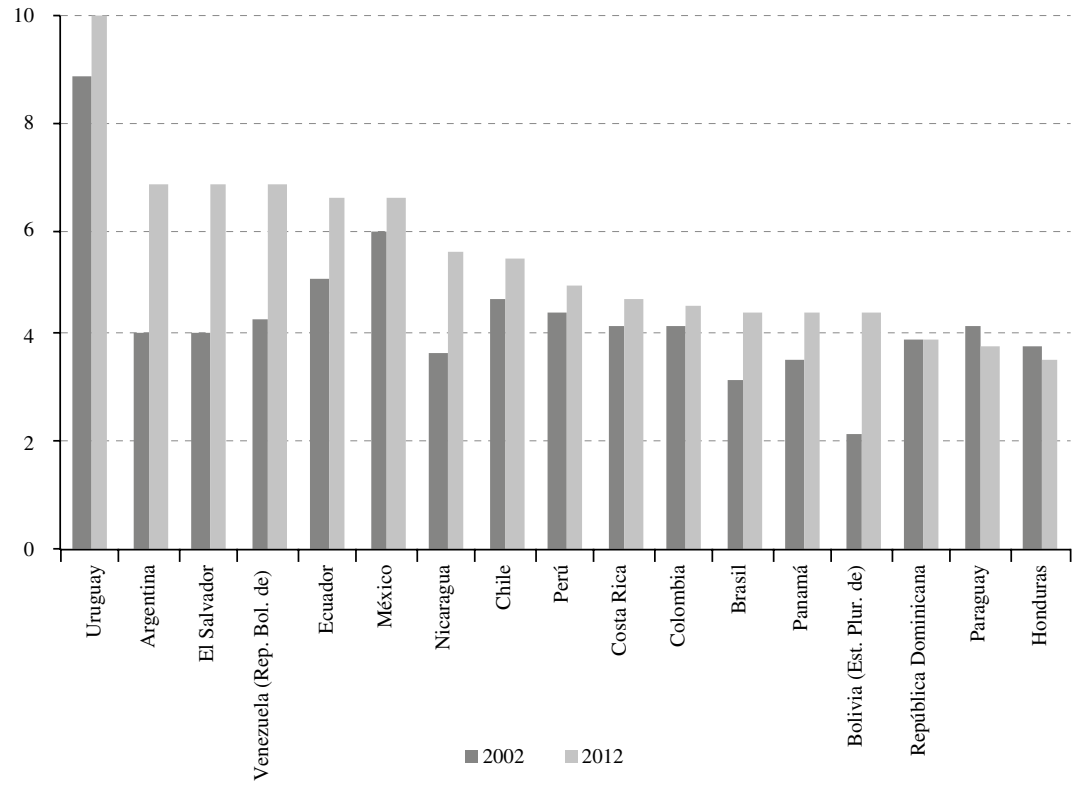

Fuente: Comisión Económica para América Latina y el Caribe (CEPAL), Panorama Social de América Latina 2013 (LC/G.2580), Santiago, 2013.

GRÁFICO 3

América Latina (17 países): participación en los ingresos totales del quintil más rico, alrededor de 2002 y 2012

(En porcentajes)

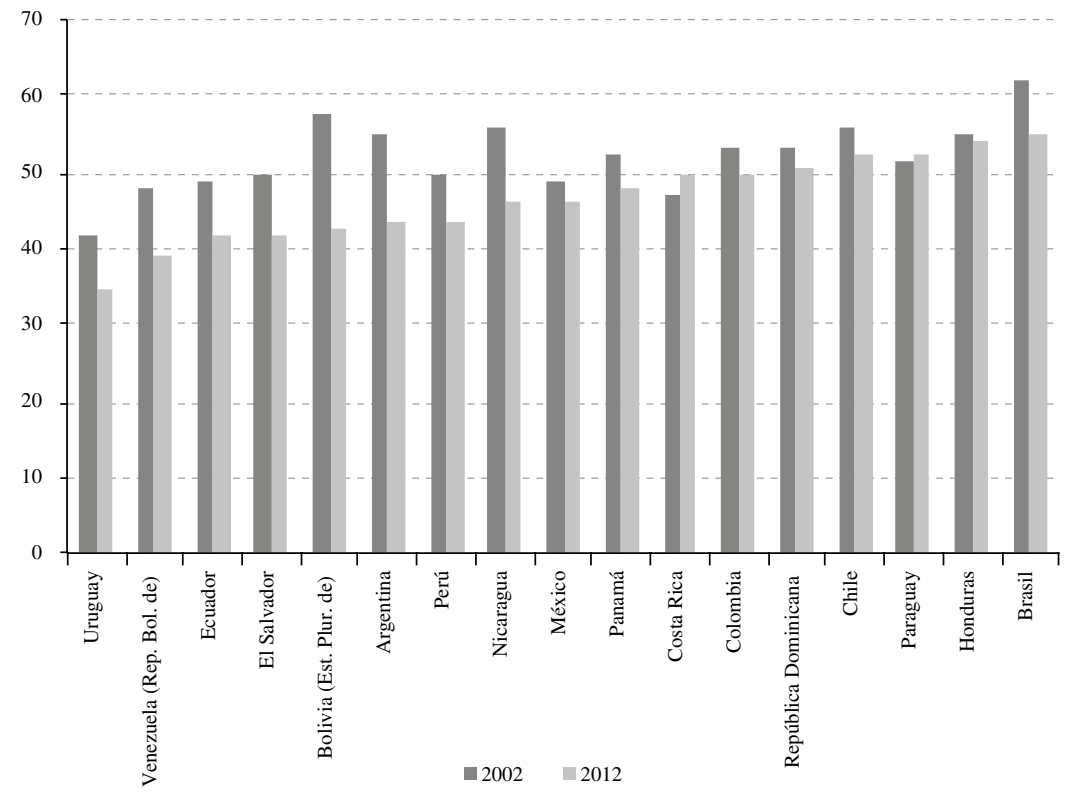

Fuente: Comisión Económica para América Latina y el Caribe (CEPAL), Panorama Social de América Latina 2013 (LC/G.2580), Santiago, 2013. 
GRÁFICO 4

América Latina (18 países): evolución de la prima laboral por calificación (en relación con el grupo sin educación), 2002 y 2011

(En porcentajes)

a) Educación secundaria completa

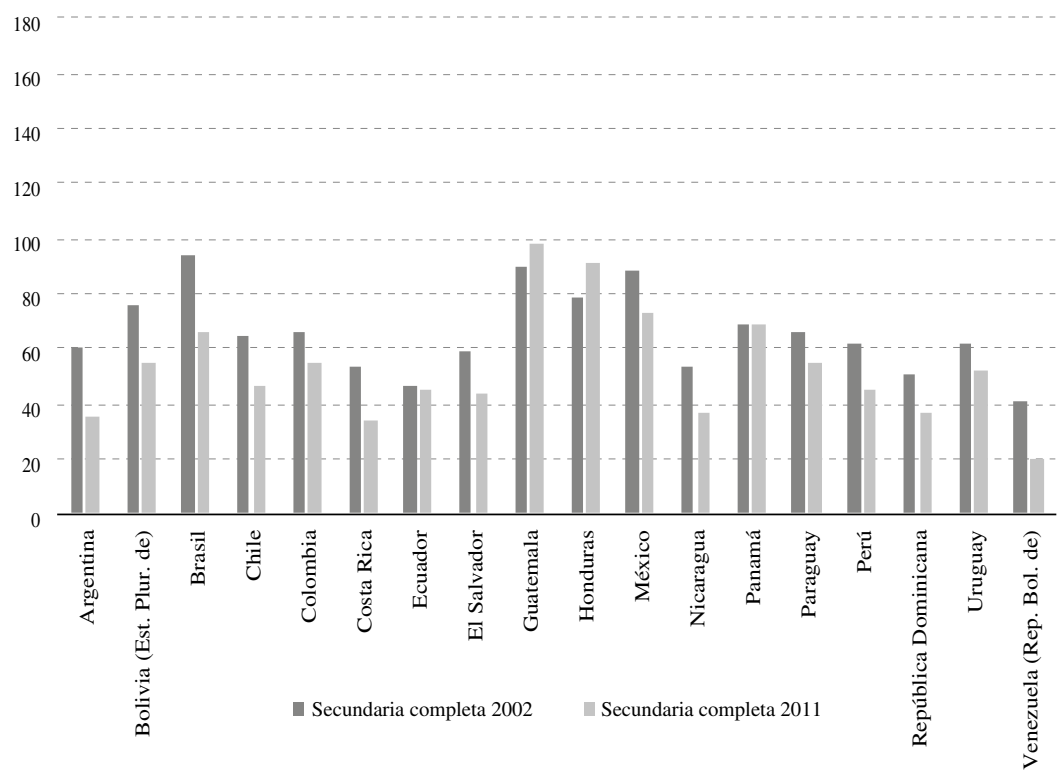

b) Educación terciaria

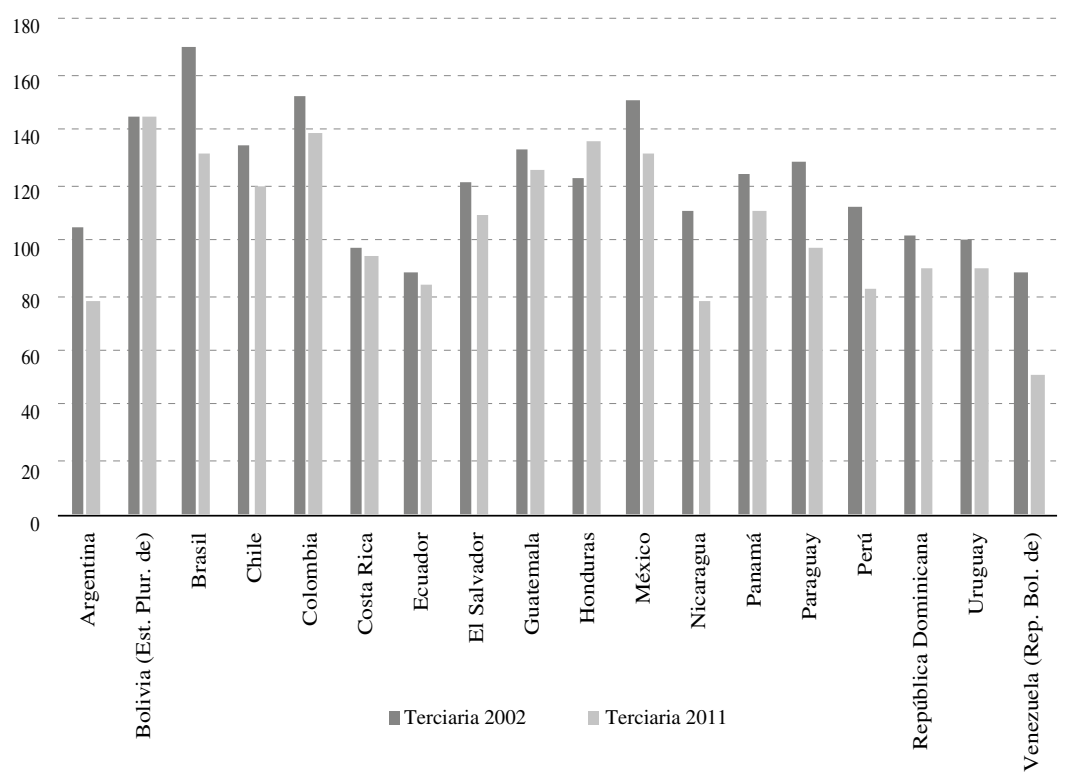

Fuente: Comisión Económica para América Latina y el Caribe (CEPAL) (2014), Pactos para la igualdad: hacia un futuro sostenible (LC/ G.2586(SES.35/3), Santiago.

Estos cambios distributivos han tenido lugar en un contexto político diferente al de las décadas anteriores. La vida democrática ha llevado a nuevas preferencias electorales y a mayor visibilización de demandas sociales. Esto ha conducido a que, en un ciclo positivo de estabilidad económica, los gobiernos respondieran a tales demandas de inclusión social con políticas de mayor sesgo redistributivo (Roberts, 2014). Otros 
autores prefieren hablar de reformas inspiradas por una "redistribución prudente con crecimiento" (Cornia, 2010), a través de políticas fiscales, laborales y de transferencias progresivas. Las políticas redistributivas y las reformas sociales no han sido patrimonio exclusivo de los gobiernos de izquierda en la región, sino que la institucionalización de la competencia electoral en contextos de alta desigualdad económica y social parece haber conducido a que partidos y gobiernos de diverso perfil ideológico se esfuercen por responder a las demandas populares de igualdad e inclusión social (Roberts, 2014).

De este modo, es probable que el rasgo distintivo de la última década en América Latina haya sido la mejora distributiva. A continuación, se analiza si estos cambios distributivos en el interior de los países de la región durante el último decenio han estado acompañados de mejoras en la distribución de los ingresos entre los latinoamericanos, o si han implicado incrementos en las brechas.

\section{IV \\ Los datos para el cálculo de la desigualdad regional}

Con el propósito de estimar la desigualdad regional, se construyó una base de datos en la que se combinan algunas variables de las encuestas de hogares de 18 países de la región, en dos momentos del tiempo: alrededor de 2002 y alrededor de $2012^{6}$. Estos 18 países comprenden el $96 \%$ de la población total de América Latina. Los detalles sobre los tamaños muestrales, la distribución de la población por país y los años de las encuestas utilizadas pueden encontrarse en el cuadro 1. Las variables fundamentales que se toman de dichas encuestas son las referidas al ingreso de los hogares, y han sido homologadas por la Comisión Económica para América Latina y el Caribe (CEPAL) a objeto de estimar, entre otros factores, la incidencia de la pobreza en la región ${ }^{7}$. Se consideran dos vectores de ingresos. En primer lugar, el ingreso per cápita de los hogares, corregido para estimar la no respuesta en las encuestas y ajustado por paridad del poder adquisitivo (PPA) $)^{8}$. Como

\footnotetext{
${ }^{6}$ Haití y Cuba no se incorporan en el análisis, ya que las fuentes de información necesarias no están disponibles.

7 Otra opción para reflejar el bienestar de los hogares consiste en considerar el consumo en lugar del ingreso de los hogares. En la región también se realizan periódicamente encuestas de gastos e ingresos, que recogen el gasto en consumo que realizan los hogares. Sin embargo, no están disponibles en los mismos puntos en el tiempo para un amplio conjunto de países, como sí lo están las encuestas de hogares. ${ }^{8}$ Los ingresos fueron llevados al año 2005 mediante la variación observada en el índice de precios al consumidor (IPC) general de cada país, de manera de aplicar los factores de PPA estimados para ese año. En el caso de la Argentina, a partir de 2007 se utilizó como deflactor el promedio simple de los índices de precios de cinco provincias. Véase Banco Mundial, Indicadores del Desarrollo Mundial [en línea] http://data.worldbank.org/data-catalog/world-development-indicators.
}

una forma alternativa de igualar el poder adquisitivo de los hogares, que permita analizar la robustez de los resultados, se utilizan como deflactores de precios las líneas de pobreza (LP) calculadas por la CEPAL para la estimación de la pobreza al nivel regional. Dichas líneas representan el costo de adquirir una canasta básica de alimentos y de bienes que satisfagan otras necesidades básicas, y puede asumirse que, por lo tanto, reflejan las diferencias en el costo de alcanzar un nivel de bienestar similar entre países. Para mantener la concordancia con la forma en que dichas líneas son empleadas para el cálculo de la pobreza por la CEPAL, en este caso se utiliza el vector de ingreso per cápita de los hogares ajustado a los valores de cuentas nacionales (véase CEPAL, 2013) .

Es importante destacar que la elección del vector de precios para realizar las comparaciones entre países es un paso metodológico de relevancia. Las mediciones de desigualdad y pobreza globales son sensibles al vector de precios que se utilice para comparar los ingresos entre países (Chen y Ravallion, 2010; Ravallion, Chen y Sangraula, 2009; Milanovic, 2012). El nuevo vector de PPA de 2005, calculado por el Programa de Comparación International, ha implicado una estimación

\footnotetext{
${ }^{9}$ Cabe señalar que existen dos bases de datos que compilan las encuestas de hogares de la región, construyendo variables homologadas de ingresos para los distintos países. Una de ellas es la de la CEPAL, en la que se basa el presente trabajo, y otra es la base de datos elaborada por el Centro de Estudios Distributivos Laborales y Sociales (CEDLAS) de la Universidad Nacional de La Plata y el Banco Mundial, denominada Base de Datos Socioeconómicos para América Latina y el Caribe (SEDLAC).
} 
de niveles mayores de precios para la mayoría de los países pobres, y por lo tanto, los niveles de desigualdad global se incrementan en más de cinco puntos en relación con los calculados mediante el vector de PPA anterior
(Milanovic, 2012). Como se verá más adelante, los resultados que se presentan en este artículo son robustos a los dos vectores de precios utilizados en el trabajo para comparar entre países.

CUADRO 1

Tamaños muestrales de las encuestas de hogares en la región y poblacióna

\begin{tabular}{|c|c|c|c|c|c|c|}
\hline Alrededor de 2002 & $\begin{array}{c}\text { Casos } \\
\text { muestrales } \\
\text { (en miles) }\end{array}$ & $\begin{array}{l}\text { Distribución } \\
\text { porcentual } \\
\text { casos } \\
\text { muestrales }\end{array}$ & $\begin{array}{c}\text { Casos } \\
\text { expandidos } \\
\text { (en miles) }\end{array}$ & $\begin{array}{l}\text { Distribución } \\
\text { porcentual } \\
\text { casos } \\
\text { expandidos }\end{array}$ & $\begin{array}{l}\text { Población } \\
\text { (en miles) }\end{array}$ & $\begin{array}{c}\text { Distribución } \\
\text { porcentual de } \\
\text { la población }\end{array}$ \\
\hline Argentina 2002 & 22832 & 4 & 24546 & 5 & 36906 & 7 \\
\hline $\begin{array}{l}\text { Bolivia (Estado Plurinacional } \\
\text { de) } 2002\end{array}$ & 5746 & 1 & 8488 & 2 & 8362 & 2 \\
\hline Brasil 2002 & 105984 & 20 & 173104 & 36 & 174506 & 33 \\
\hline Chile 2000 & 65007 & 13 & 15033 & 3 & 15455 & 3 \\
\hline Colombia 2002 & 129164 & 25 & 39767 & 8 & 39900 & 8 \\
\hline Costa Rica 2002 & 11094 & 2 & 3991 & 1 & 3930 & 1 \\
\hline Ecuador 2002 & 6030 & 1 & 8288 & 2 & 12567 & 2 \\
\hline El Salvador 2001 & 11953 & 2 & 6415 & 1 & 5959 & 1 \\
\hline Guatemala 2002 & 2759 & 1 & 11556 & 2 & 11204 & 2 \\
\hline Honduras 2002 & 22010 & 4 & 6668 & 1 & 6236 & 1 \\
\hline México 2002 & 17167 & 3 & 101522 & 21 & 101721 & 20 \\
\hline Nicaragua 2001 & 4191 & 1 & 5193 & 1 & 5101 & 1 \\
\hline Panamá 2002 & 13404 & 3 & 2991 & 1 & 3053 & 1 \\
\hline Perú 2001 & 16515 & 3 & 26660 & 6 & 5350 & 1 \\
\hline Paraguay 2001 & 8131 & 2 & 5333 & 1 & 26004 & 5 \\
\hline República Dominicana 2002 & 5720 & 1 & 8553 & 2 & 8575 & 2 \\
\hline Uruguay 2002 & 18421 & 4 & 2678 & 1 & 3321 & 1 \\
\hline $\begin{array}{l}\text { Venezuela (República } \\
\text { Bolivariana de) } 2002\end{array}$ & 53124 & 10 & 25767 & 5 & 24408 & 5 \\
\hline América Latina & 519252 & 100 & 476556 & 100 & 521429 & 100 \\
\hline \multicolumn{7}{|l|}{ Alrededor de 2011} \\
\hline Argentina 2012 & 69293 & 10 & 25351 & 5 & 40370 & 7 \\
\hline $\begin{array}{l}\text { Bolivia (Estado Plurinacional } \\
\text { de) } 2011\end{array}$ & 8851 & 1 & 10691 & 2 & 9995 & 2 \\
\hline Brasil 2012 & 114906 & 16 & 196723 & 36 & 195153 & 33 \\
\hline Chile 2011 & 59084 & 8 & 16941 & 3 & 17149 & 3 \\
\hline Colombia 2012 & 228662 & 33 & 45029 & 8 & 46448 & 8 \\
\hline Costa Rica 2012 & 11374 & 2 & 4661 & 1 & 4669 & 1 \\
\hline Ecuador 2012 & 19840 & 3 & 14676 & 3 & 15018 & 3 \\
\hline El Salvador 2012 & 21710 & 3 & 6245 & 1 & 6218 & 1 \\
\hline Guatemala 2006 & 13686 & 2 & 12966 & 2 & 14334 & 2 \\
\hline Honduras 2010 & 7043 & 1 & 8041 & 1 & 7619 & 1 \\
\hline México 2012 & 9002 & 1 & 117284 & 21 & 115301 & 20 \\
\hline Nicaragua 2009 & 6515 & 1 & 5755 & 1 & 5813 & 1 \\
\hline Panamá 2011 & 12379 & 2 & 3624 & 1 & 3676 & 1 \\
\hline Perú 2012 & 25091 & 4 & 30533 & 6 & 6458 & 1 \\
\hline Paraguay 2011 & 4894 & 1 & 6465 & 1 & 29272 & 5 \\
\hline República Dominicana 2012 & 8163 & 1 & 10077 & 2 & 9907 & 2 \\
\hline Uruguay 2012 & 43839 & 6 & 3373 & 1 & 3373 & 1 \\
\hline $\begin{array}{l}\text { Venezuela (República } \\
\text { Bolivariana de) } 2012\end{array}$ & 37643 & 5 & 28819 & 5 & 29039 & 5 \\
\hline América Latina & 701975 & 100 & 547256 & 100 & 590082 & 100 \\
\hline
\end{tabular}

Fuente: Elaboración propia sobre la base de datos de las encuestas de hogares de los respectivos países y Centro Latinoamericano y Caribeño de Demografía (CElade) - División de Población de la CEPAl, Base de datos de población.

a Más detalles sobre las bases de datos utilizadas pueden encontrarse en http://interwp.cepal.org/badehog/acercade.asp. 


\section{V}

\section{Los ingresos promedio de los latinoamericanos}

Una primera consideración del PIB y los ingresos promedio de los países de la región resulta ilustrativa de las importantes diferencias (véase el cuadro 2). El ordenamiento de los países es similar en ambos casos, aunque no igual (véase el gráfico 5). Si se consideran los datos de 2011, Chile es el país con mayor PIB per cápita en la región (21.011 dólares a paridad del poder adquisitivo (PPA)), mientras que el Uruguay es el que presenta mayor ingreso per cápita de los hogares (554 dólares a paridad del poder adquisitivo (PPA)).

La relación entre el país más rico y el más pobre en términos del PIB per cápita (Chile y Nicaragua, respectivamente), pasó de 4,0 a 5,5 entre 2002 y 2011. También en términos de ingreso per cápita de los hogares las diferencias promedio se han ampliado: la razón pasa de 3,0 en 2002 (entre Chile y Nicaragua) a 3,7 en 2012 (entre el Uruguay y Nicaragua). Chile es el país donde la relación entre el ingreso per cápita de los hogares y la línea de pobreza es superior $(3,6$ en el año inicial y 4,2 en el año final), mientras que el mínimo de esta relación se presenta en Honduras ( 0,9 y 1,0 en los años inicial y final, respectivamente). La relación entre el valor máximo y el mínimo del ingreso per cápita expresado en relación con la línea de pobreza (LP) se reduce en el período. El coeficiente de variación de las tres variables se ha ampliado durante el lapso (aunque levemente en el caso del ingreso relativo a la $\mathrm{LP}$ ).

América Latina: PIB e ingreso per cápita (en dólares en PPA) de los hogares, 2002, 2011 y 2012

\begin{tabular}{|c|c|c|c|c|c|c|}
\hline & \multicolumn{2}{|c|}{$\begin{array}{l}\text { PIB per cápita } \\
\text { (en dólares de } 2005 \\
\text { expresados en PPA) }\end{array}$} & \multicolumn{2}{|c|}{$\begin{array}{c}\text { Ingreso per cápita de los } \\
\text { hogares (en dólares de } \\
2005 \text { expresados en PPA) } \\
\text { (mensual) }\end{array}$} & \multicolumn{2}{|c|}{$\begin{array}{c}\text { Ingreso per cápita de los } \\
\text { hogares (relativo a la línea } \\
\text { de pobreza (LP) })^{b}\end{array}$} \\
\hline & 2002 & 2011 & 2002 & 2012 & 2002 & 2012 \\
\hline Argentina ${ }^{a}$ & 7948 & $\ldots$ & 281 & 482 & 2,1 & 3,7 \\
\hline Bolivia (Estado Plurinacional de) & 3229 & 4936 & 189 & 273 & 1,4 & 1,9 \\
\hline Brasil & 7395 & 11515 & 316 & 445 & 3,0 & 4,2 \\
\hline Chile & 10413 & 21001 & 363 & 427 & 3,6 & 4,2 \\
\hline Colombia & 6154 & 9973 & 213 & 311 & 1,8 & 2,4 \\
\hline Costa Rica & 7491 & 12074 & 327 & 433 & 3,0 & 3,3 \\
\hline Ecuador & 5954 & 9155 & 290 & 311 & 1,7 & 2,0 \\
\hline El Salvador & 4920 & 6785 & 228 & 189 & 1,5 & 1,4 \\
\hline Guatemala & 3717 & 4914 & 189 & 223 & 1,3 & 1,6 \\
\hline Honduras & 2724 & 4031 & 174 & 171 & 0,9 & 1,0 \\
\hline México & 10361 & 16044 & 305 & 335 & 2,0 & 1,9 \\
\hline Nicaragua & 2572 & 3797 & 143 & 151 & 1,1 & 1,2 \\
\hline Panamá & 7190 & 14756 & 318 & 356 & 2,4 & 3,0 \\
\hline Perú & 5219 & 10076 & 190 & 304 & 1,4 & 2,2 \\
\hline Paraguay & 4025 & 6112 & 252 & 333 & 1,3 & 1,6 \\
\hline República Dominicana & 5539 & 9617 & 247 & 228 & 1,8 & 2,0 \\
\hline Uruguay & 7819 & 14970 & 430 & 554 & 3,1 & 3,7 \\
\hline Venezuela (República Bolivariana de) & 7997 & 12534 & 172 & 289 & 1,6 & 2,2 \\
\hline Promedio simple & 6148 & 10135 & 257 & 323 & 1,9 & 2,4 \\
\hline Máximo & 10413 & 21001 & 430 & 554 & 4 & 4 \\
\hline Mínimo & 2572 & 3797 & 142,74 & 151,4 & 0,9 & 1 \\
\hline Razón máx./mín. & 4,0 & 5,5 & 3,0 & 3,7 & 4,3 & 4,0 \\
\hline Coeficiente de variación & 0,39 & 0,47 & 0,30 & 0,35 & 0,40 & 0,42 \\
\hline
\end{tabular}

Fuente: Elaboración propia sobre la base de Banco Mundial, Indicadores del Desarrollo Mundial y datos de las encuestas de hogares de los respectivos países.

Nota: PPA: Paridad del poder adquisitivo.

a A partir de 2007 no se publican datos del producto interno bruto (PIB) per cápita en paridad del poder adquisitivo (PPA) para la Argentina.

b En el período 2002 se incluyen datos de 2000 en Chile, y de 2001 en El Salvador, Nicaragua, el Perú y el Paraguay. En el período 2012 se incluyen datos de 2011 en Bolivia (Estado Plurinacional de), Chile, Panamá y el Paraguay; de 2010 en Honduras; y de 2006 en Guatemala. 
GRÁFICO 5

América Latina (18 países): PIB e ingreso per cápita de los hogares, 2011

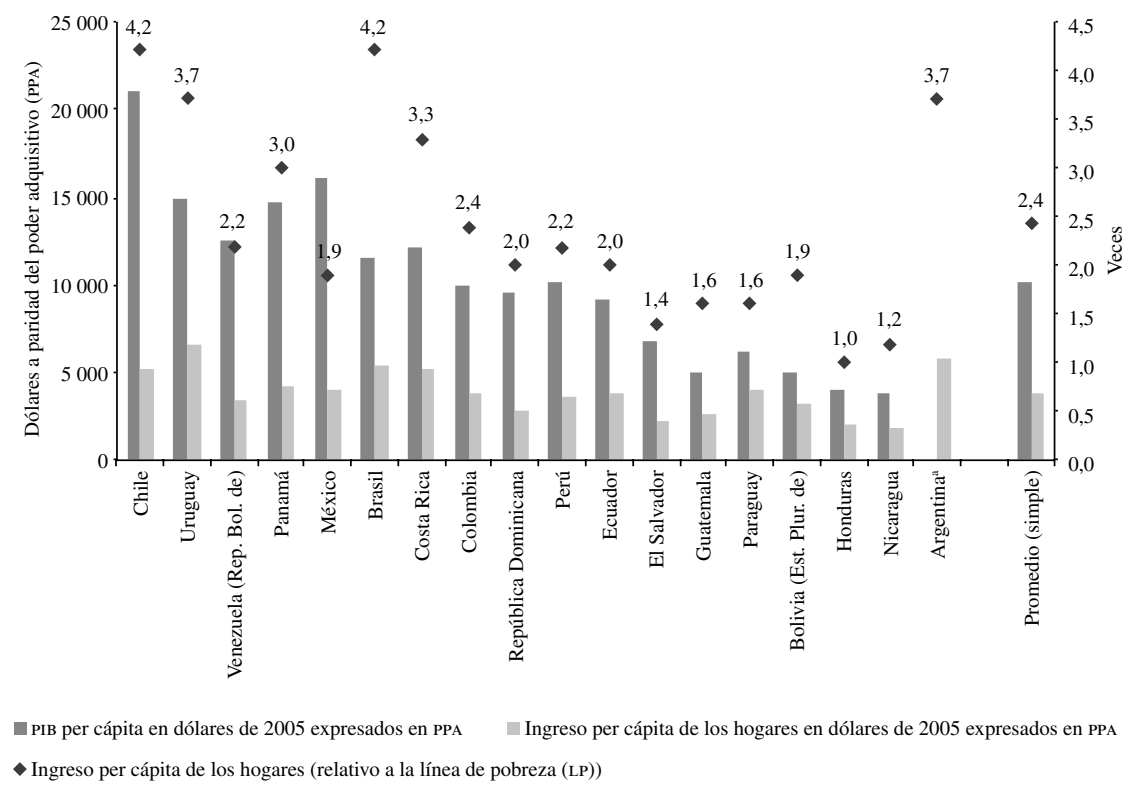

Fuente: Elaboración propia sobre la base de Banco Mundial, Indicadores del Desarrollo Mundial y datos de las encuestas de hogares de los respectivos países.

Nota: PIB: Producto interno bruto.

a A partir de 2007 no se publican datos del producto interno bruto (PIB) per cápita en paridad del poder adquisitivo (PPA) para la Argentina.

La ampliación de las diferencias promedio entre países en términos del PIB e ingreso per cápita no apoya por lo tanto la idea de convergencia en la situación promedio de los países de la región. Sin embargo, como se verá en la sección siguiente, si no se consideran las fronteras entre países y se toma la unidad de individuos en lugar de considerar promedios por país, las diferencias han disminuido.

\section{VI}

\section{La distribución del ingreso entre los latinoamericanos}

En el análisis de la desigualdad global se utilizan las herramientas estadísticas tradicionales de dicho análisis entre hogares a nivel nacional. Como se discutió anteriormente, el primer paso consiste en la construcción de un vector de ingresos comparable entre los países de la región. Los resultados que se presentan a continuación surgen al considerar los valores del ingreso en dólares ajustados por PPA. Los resultados al tomar en consideración la LP de la CEPAL como tasa de cambio se presentan en el anexo, ya que en términos generales son similares a los presentados en lo que sigue.
La distribución de la población de los países dentro de esos quintiles globales es un primer indicador de las diferencias de ingresos entre los países (véanse el gráfico 6 y el cuadro A.1 del anexo). En países como la Argentina, el Brasil, Chile, Costa Rica y el Uruguay, más de la mitad de la población se ubica en los dos quintiles superiores de la distribución regional. Al otro extremo, en El Salvador, Guatemala, Honduras y Nicaragua (y en menor medida en Bolivia (Estado Plurinacional de), México y la República Dominicana), más de la mitad de la población se sitúa en los dos quintiles inferiores de la 


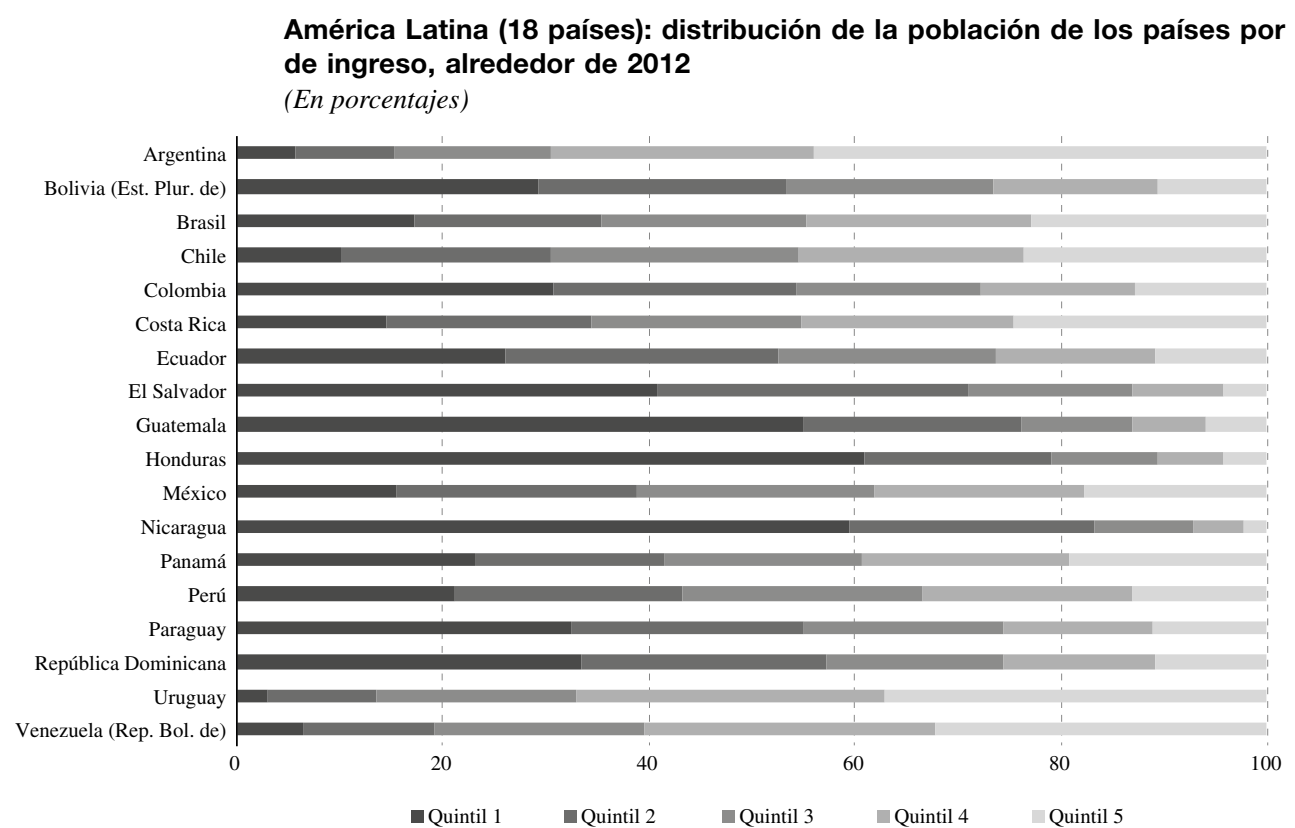

Fuente: Elaboración propia sobre la base de Banco Mundial, Indicadores del Desarrollo Mundial y datos de las encuestas de hogares de los respectivos países.

distribución regional. Como era de esperar, los países con mayor tamaño, cuya importancia en la construcción de los quintiles es más relevante, tienen su población distribuida más homogéneamente. Los resultados obtenidos al comparar los ingresos utilizando como tasa de cambio la LP, son similares (véase el cuadro A.2 del anexo).

Entre 2002 y 2012, el ingreso per cápita promedio de los habitantes de la región (expresado en paridad del poder de compra (PPA)) creció $28 \%$. Si este se considera en términos del ingreso relativo a la LP, la variación en el período es de $30 \%$. El crecimiento más pronunciado se produjo en la parte baja de la distribución, como se ilustra en el gráfico 7, donde se presenta la variación por decil y por percentil. Tanto en términos del ingreso ajustado por PPA, como en el caso del ingreso relativo a la LP, se aprecia que la variación ha sido decreciente con el nivel de ingresos. En términos de Ravallion y Chen (2003), la curva de incidencia del crecimiento (growth incidence curve) refleja que el crecimiento ha sido favorable a los pobres (pro-poor growth). Esta evolución es más marcada en el caso del ingreso ajustado por PPA, que presenta un mayor crecimiento que el ingreso ajustado por LP para los hogares de la primera mitad de la distribución del ingreso. Este mayor crecimiento de los ingresos de los individuos ubicados en la parte baja de la distribución regional es, por lo tanto, un primer indicio de caída de la desigualdad global en la región.
Esta curva de crecimiento agregado para el conjunto de los países oculta comportamientos diferenciales por grupos. Si se construyen cuatro grupos en función de la variación experimentada por el ingreso medio de los países en el período considerado, se aprecian mejor los cambios diferenciales por país (véase el gráfico 8). La variación del ingreso y la clasificación de los países en grupos se presentan en el cuadro A.3 del anexo. Mientras que algunos países muestran un patrón de crecimiento claramente favorable a los pobres (la Argentina, el Paraguay, el Uruguay y Venezuela (República Bolivariana de) son los casos extremos), en otros la curva es creciente con el ingreso, registrando crecimientos mayores de este en la parte alta de la distribución (Guatemala, Honduras y Nicaragua). Nuevamente, los resultados son similares con los dos vectores de ingresos utilizados.

Todos los indicadores de desigualdad global calculados para la región muestran un patrón similar: los niveles de desigualdad medidos considerando a América Latina en su totalidad resultan superiores a los de la mayoría de los países de la región considerados individualmente (véase el cuadro 3 ), resultado que también surge en los cálculos de desigualdad global a nivel mundial (véase, por ejemplo, Anand y Segal, 2015; Lakner y Milanovic, 2013). En segundo lugar, entre 2002 y 2012, período de sostenida caída de la desigualdad en la mayor parte de los países de la región, también los indicadores de desigualdad global muestran 
GRÁFICO 7

América Latina: variación del ingreso real de la población, 2002-2012 (En porcentajes)

a) Por deciles de la distribución regional

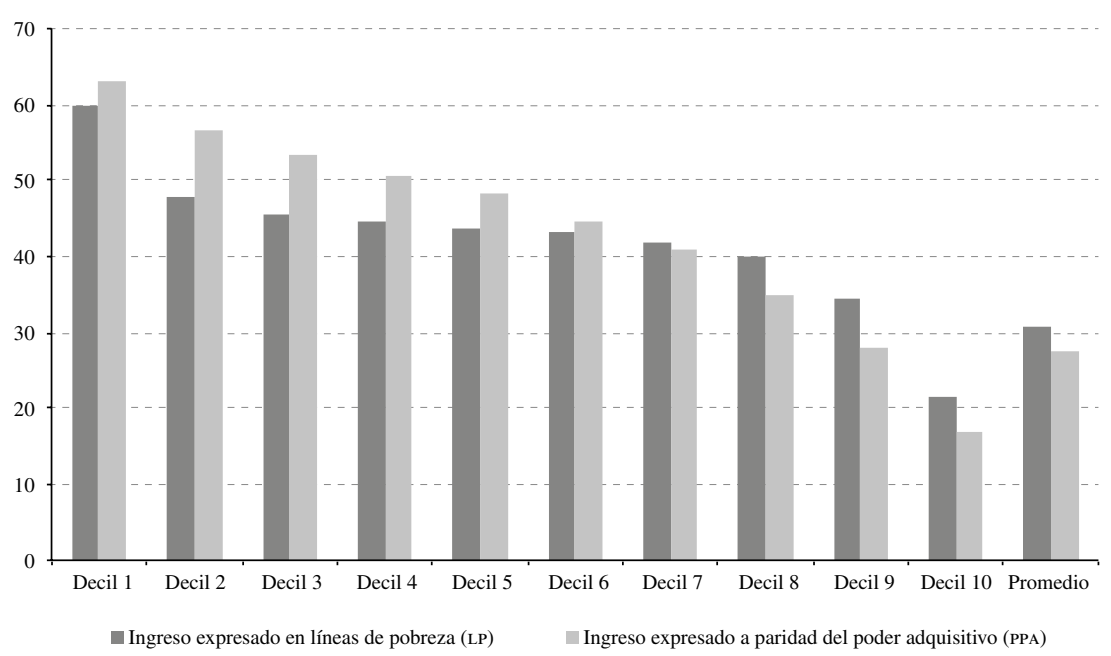

b) Por percentiles de la distribución regional

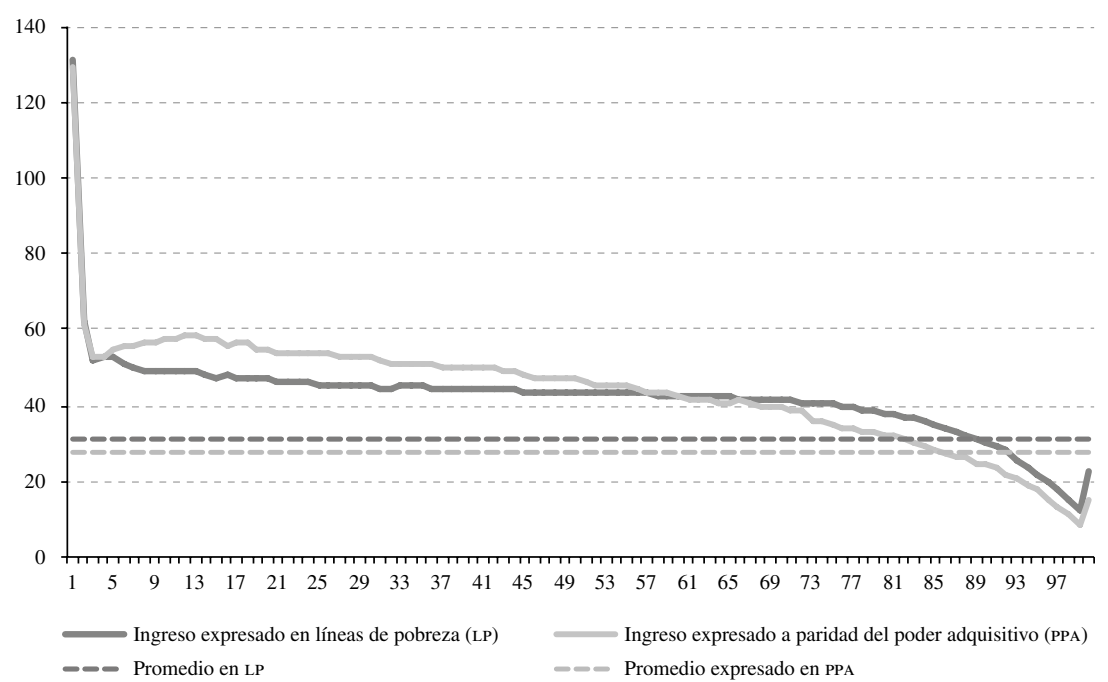

Fuente: Elaboración propia sobre la base de Banco Mundial, Indicadores del Desarrollo Mundial y datos de las encuestas de hogares de los respectivos países. 
GRÁFICO 8

América Latina: variación del ingreso de la población según grupos de países, 2002-2012

a) Ingreso expresado en PPA

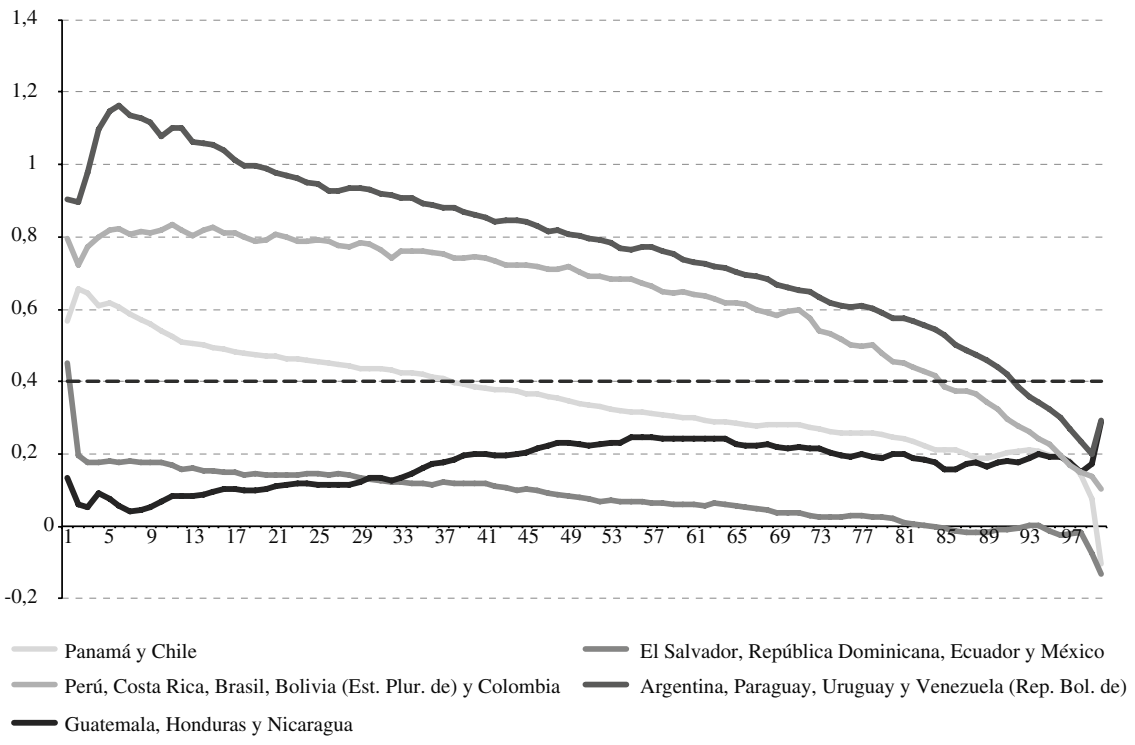

b) Ingreso expresado en líneas de pobreza (LP)

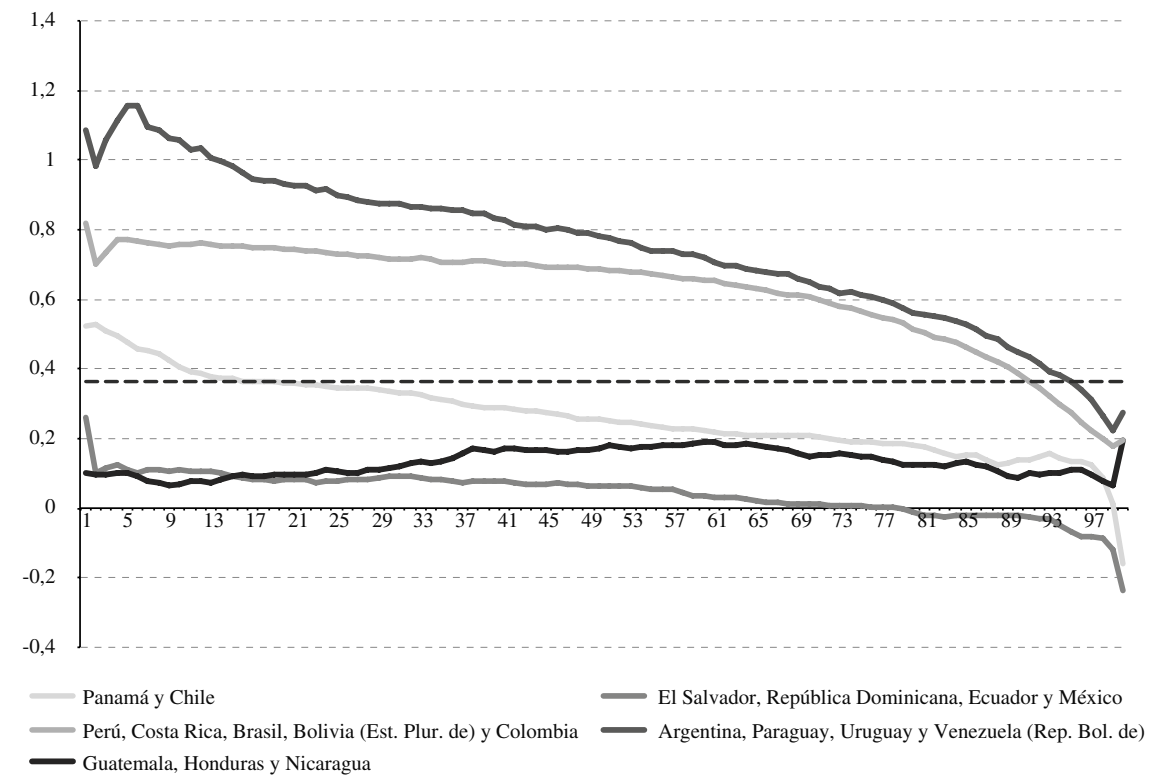

Fuente: Elaboración propia sobre la base de Banco Mundial, Indicadores del Desarrollo Mundial y datos de las encuestas de hogares de los respectivos países.

Nota: PPA: Paridad del poder adquisitivo. 


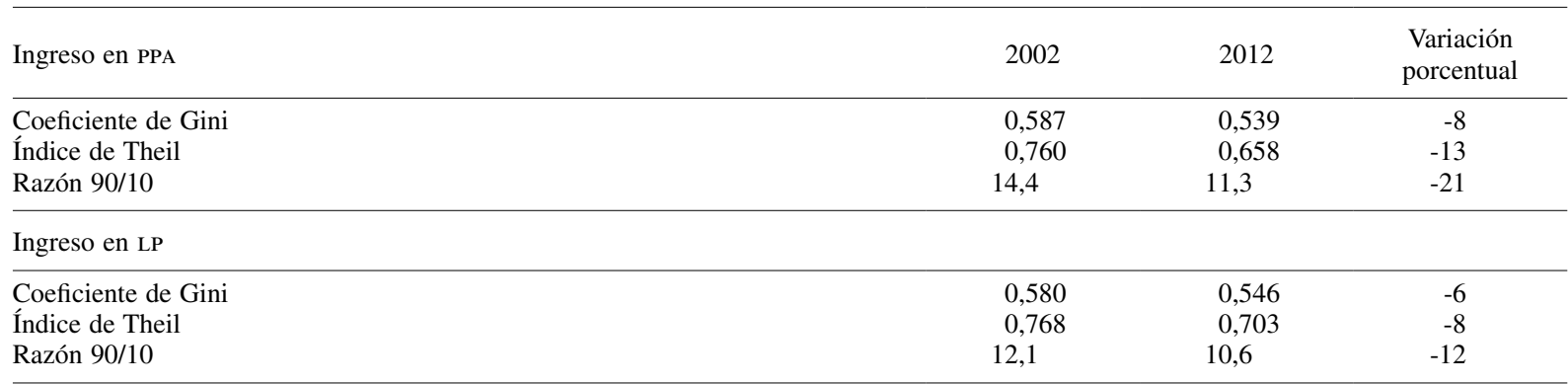

Fuente: Elaboración propia sobre la base de Banco Mundial, Indicadores del Desarrollo Mundial y datos de las encuestas de hogares de los respectivos países.

Nota: PPA: Paridad del poder adquisitivo; LP: Línea de pobreza.

un descenso significativo. En efecto, el coeficiente de Gini, el índice de Theil y la razón 90/10 presentan una disminución considerable. La caída del índice de Theil es mayor que la del coeficiente de Gini, dado que el primero pondera en mayor medida lo que sucede en la parte baja de la distribución, donde se produjeron las mayores mejoras, como ya se vio. Los resultados apuntan en la misma dirección tanto con el ingreso ajustado por PPA como el relativo a la LP.

La captación de ingresos de los percentiles más ricos de la región cae en el período, aunque se trata de una disminución muy leve, sobre todo cuando se considera el ingreso ajustado por PPA (véase el gráfico 9$)^{10}$. Una vez más los resultados indican que las distancias entre toda la población de la región son menores que hace una década atrás, reafirmando el resultado de retroceso de la desigualdad regional considerada globalmente.

10 Este indicador está calculado sobre la base de información de encuestas de hogares y, por lo tanto, en él se sobreestima la verdadera captación de los percentiles más altos, cuyos ingresos tienden a no ser reflejados adecuadamente en este tipo de encuestas.

América Latina: captación del ingreso de los percentiles superiores, 2002-2012 (En porcentajes)

a) Ingreso expresado en LP

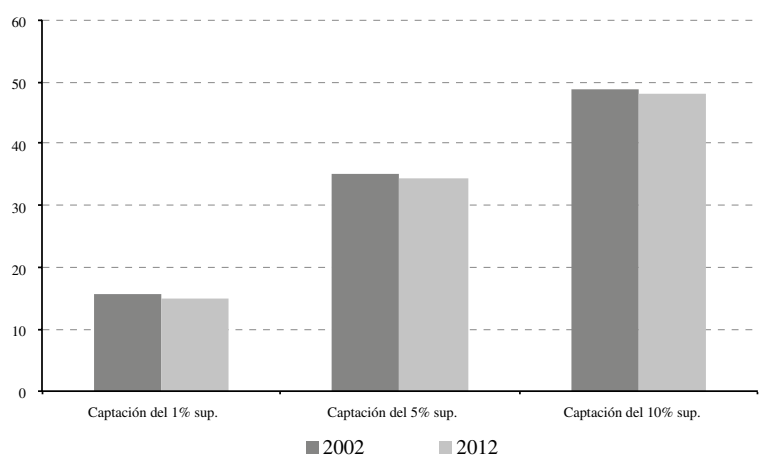

b) Ingreso expresado en PPA

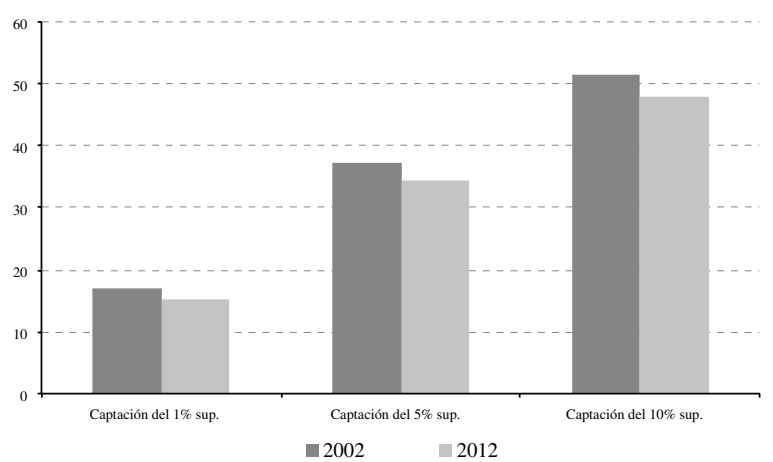

Fuente: Elaboración propia sobre la base de Banco Mundial, Indicadores del Desarrollo Mundial y datos de las encuestas de hogares de los respectivos países.

Nota: LP: Línea de pobreza; PPA: Paridad del poder adquisitivo. 
La desigualdad de ingresos entre los individuos de la región puede descomponerse en la desigualdad entre países y la desigualdad dentro de los países. La primera equivale a considerar la desigualdad entre todos los individuos de la región, suponiendo que cada uno de ellos tiene un ingreso igual al ingreso per cápita promedio de su país. La desigualdad intragrupal o en el interior de los países, en tanto, es un promedio ponderado de los indicadores de desigualdad nacionales, donde los ponderadores son dados por la importancia del ingreso de cada país en el ingreso total de América Latina.

Con el propósito de visualizar esta descomposición de la desigualdad global regional se considera el índice de Theil, que cumple la propiedad de descomposición. Un primer aspecto que surge de esta descomposición es que la mayor parte de la desigualdad regional corresponde a la desigualdad dentro de los países (véase el cuadro 4). En efecto, alrededor del $90 \%$ de la desigualdad global en la región obedece a diferencias en el interior de los países. Este resultado difiere del que surge de las descomposiciones mundiales, que indican que entre el $80 \%$ y el $90 \%$ de la desigualdad global a nivel del mundo (dependiendo de las medidas y años considerados) deriva de diferencias en los ingresos medios entre países (Anand y Segal, 2015). Al restringir el análisis a los países de América Latina se detecta una mayor homogeneidad entre estos, lo que resulta esperable al reducir la cantidad de países incluidos en el cálculo; y a su vez, la desigualdad dentro de los países es la que determina casi totalmente la desigualdad regional. Estos resultados indican que las dinámicas internas de los países, vinculadas con sus realidades sociales, institucionales y políticas, resultan más relevantes para la consideración de la desigualdad regional que las dinámicas entre países (como por ejemplo, las vinculadas a la migración o el comercio). Por otra parte, es válido recordar que la contribución de cada país a la desigualdad depende principalmente de su participación en los ingresos totales de los hogares de la región, y por lo tanto, se destaca la importancia del Brasil y México (véase el cuadro A.4 del anexo).

Un segundo aspecto por destacar de este ejercicio de descomposición es que la reducción de la desigualdad global de la región en el período se explica sobre todo por la disminución de la desigualdad en el interior de los países. Nuevamente, en este resultado tienen mucha importancia los procesos de mejora distributiva que han tenido lugar en el Brasil y México. La relevancia del componente de desigualdad entre países (que refleja diferencias en los ingresos medios por país) se ha incrementado, de manera consistente, con la tendencia a la mayor divergencia de ingresos promedio discutida en la sección V. La desigualdad entre países explica una parte menor, aunque creciente, de la desigualdad global en la región. Estos resultados indican que las condiciones de vida de los habitantes de América Latina son hoy más igualitarias en términos relativos que hace una década, aunque las diferencias en los ingresos promedio de los países son mayores. Cabe señalar que los resultados sobre el descenso de la desigualdad global en la región, así como la prevalencia absoluta de la desigualdad dentro de los países y su efecto desconcentrador, son similares (aunque más marcados) a los reportados en Gasparini y otros (2008) para el período 1992-2006.

Descomposición del índice de Theil para América Latina, 2002 y 2012

\begin{tabular}{|c|c|c|c|c|c|}
\hline & \multicolumn{2}{|c|}{ Índice de Theil } & \multicolumn{2}{|c|}{$\begin{array}{c}\text { Importancia de los componentes } \\
\text { (porcentajes) }\end{array}$} & \multirow{2}{*}{$\begin{array}{c}\text { Variación porcentual } \\
2012-2002\end{array}$} \\
\hline & 2002 & 2012 & 2002 & 2012 & \\
\hline \multicolumn{6}{|l|}{ Ingreso en LP } \\
\hline Intrapaíses & 72,4 & 63,2 & 94 & 90 & -13 \\
\hline Entre países & 4,5 & 7,1 & 6 & 10 & 60 \\
\hline Índice deTheil & 76,8 & 70,3 & 100 & 100 & -8 \\
\hline \multicolumn{6}{|l|}{ Ingreso en PPA } \\
\hline Intrapaíses & 72,9 & 61,7 & 95 & 88 & -15 \\
\hline Entre países & 3,1 & 4,1 & 4 & 6 & 33 \\
\hline Índice de Theil & 76,0 & 65,8 & 100 & 100 & -13 \\
\hline
\end{tabular}

Fuente: Elaboración propia sobre la base de Banco Mundial, Indicadores del Desarrollo Mundial y datos de las encuestas de hogares de los respectivos países.

Nota: PPA: Paridad del poder adquisitivo; LP: Línea de pobreza. 


\section{VII}

\section{Comentarios finales}

El crecimiento del ingreso experimentado por los hogares latinoamericanos en la última década ha sido más pronunciado entre los hogares y personas del estrato bajo de la distribución, más allá de las diferencias que se detectan por países. Esto ha conducido a que la desigualdad global de la región presente una disminución entre 2002 y 2012, lo que indica que las condiciones de vida de los habitantes de América Latina son más igualitarias al final de la década que al comienzo de esta. Tales resultados son robustos a los dos vectores de precios utilizados para comparar ingresos entre países.
Si bien los ingresos de los individuos de América Latina en su conjunto son menos desiguales hoy que hace una década, este resultado proviene de dos efectos contrarios: una caída de la desigualdad en la mayor parte de los países y un aumento de las diferencias en los ingresos promedio por país. Aun cuando el segundo efecto es muy leve, queda en evidencia que el crecimiento de las brechas de ingreso entre los países de la región puede convertirse en un factor que atente contra la reducción de la desigualdad desde una perspectiva regional. 
ANEXO

CUADRO A.1

América Latina (18 países): distribución de la población por quintiles del ingreso regionala, 2002 y 2012

(En porcentajes)

\begin{tabular}{|c|c|c|c|c|c|c|c|}
\hline & & Quintil 1 & Quintil 2 & Quintil 3 & Quintil 4 & Quintil 5 & Total \\
\hline Argentina & $\begin{array}{l}2002 \\
2012\end{array}$ & $\begin{array}{r}14,1 \\
5,6\end{array}$ & $\begin{array}{r}17,1 \\
9,5\end{array}$ & $\begin{array}{l}19,1 \\
15,4\end{array}$ & $\begin{array}{l}22,7 \\
25,4\end{array}$ & $\begin{array}{l}27,1 \\
44,0\end{array}$ & $\begin{array}{l}100,0 \\
100,0\end{array}$ \\
\hline Bolivia (Estado Plurinacional de) & $\begin{array}{l}2002 \\
2011\end{array}$ & $\begin{array}{l}39,8 \\
29,1\end{array}$ & $\begin{array}{l}22,2 \\
24,1\end{array}$ & $\begin{array}{l}15,8 \\
20,1\end{array}$ & $\begin{array}{l}12,7 \\
16,0\end{array}$ & $\begin{array}{r}9,6 \\
10,6\end{array}$ & $\begin{array}{l}100,0 \\
100,0\end{array}$ \\
\hline Brasil & $\begin{array}{l}2002 \\
2012\end{array}$ & $\begin{array}{l}22,0 \\
17,3\end{array}$ & $\begin{array}{l}20,0 \\
18,0\end{array}$ & $\begin{array}{l}19,0 \\
19,9\end{array}$ & $\begin{array}{l}18,3 \\
21,9\end{array}$ & $\begin{array}{l}20,6 \\
22,9\end{array}$ & $\begin{array}{l}100,0 \\
100,0\end{array}$ \\
\hline Chile & $\begin{array}{l}2000 \\
2011\end{array}$ & $\begin{array}{r}9,5 \\
10,0\end{array}$ & $\begin{array}{l}18,5 \\
20,4\end{array}$ & $\begin{array}{l}22,7 \\
24,2\end{array}$ & $\begin{array}{l}24,3 \\
21,8\end{array}$ & $\begin{array}{l}25,0 \\
23,6\end{array}$ & $\begin{array}{l}100,0 \\
100,0\end{array}$ \\
\hline Colombia & $\begin{array}{l}2002 \\
2012\end{array}$ & $\begin{array}{l}30,5 \\
30,8\end{array}$ & $\begin{array}{l}24,6 \\
23,4\end{array}$ & $\begin{array}{l}19,4 \\
18,0\end{array}$ & $\begin{array}{l}14,3 \\
15,0\end{array}$ & $\begin{array}{l}11,1 \\
12,8\end{array}$ & $\begin{array}{l}100,0 \\
100,0\end{array}$ \\
\hline Costa Rica & $\begin{array}{l}2002 \\
2012\end{array}$ & $\begin{array}{l}10,7 \\
14,4\end{array}$ & $\begin{array}{l}13,7 \\
20,0\end{array}$ & $\begin{array}{l}21,3 \\
20,4\end{array}$ & $\begin{array}{l}26,4 \\
20,5\end{array}$ & $\begin{array}{l}27,9 \\
24,7\end{array}$ & $\begin{array}{l}100,0 \\
100,0\end{array}$ \\
\hline Ecuador & $\begin{array}{l}2002 \\
2012\end{array}$ & $\begin{array}{l}17,8 \\
26,2\end{array}$ & $\begin{array}{l}23,4 \\
26,5\end{array}$ & $\begin{array}{l}24,3 \\
20,9\end{array}$ & $\begin{array}{l}20,9 \\
15,6\end{array}$ & $\begin{array}{l}13,6 \\
10,9\end{array}$ & $\begin{array}{l}100,0 \\
100,0\end{array}$ \\
\hline El Salvador & $\begin{array}{l}2001 \\
2012\end{array}$ & $\begin{array}{l}29,6 \\
40,7\end{array}$ & $\begin{array}{l}23,0 \\
30,3\end{array}$ & $\begin{array}{l}20,1 \\
15,8\end{array}$ & $\begin{array}{r}16,3 \\
9,0\end{array}$ & $\begin{array}{r}11,1 \\
4,3\end{array}$ & $\begin{array}{l}100,0 \\
100,0\end{array}$ \\
\hline Guatemala & $\begin{array}{l}2002 \\
2006\end{array}$ & $\begin{array}{l}31,4 \\
55,0\end{array}$ & $\begin{array}{l}27,1 \\
21,0\end{array}$ & $\begin{array}{l}17,1 \\
10,8\end{array}$ & $\begin{array}{r}14,0 \\
7,1\end{array}$ & $\begin{array}{r}10,5 \\
6,0\end{array}$ & $\begin{array}{l}100,0 \\
100,0\end{array}$ \\
\hline Honduras & $\begin{array}{l}2002 \\
2010\end{array}$ & $\begin{array}{l}53,6 \\
60,8\end{array}$ & $\begin{array}{l}19,9 \\
18,3\end{array}$ & $\begin{array}{l}13,0 \\
10,3\end{array}$ & $\begin{array}{l}8,3 \\
6,4\end{array}$ & $\begin{array}{l}5,3 \\
4,2\end{array}$ & $\begin{array}{l}100,0 \\
100,0\end{array}$ \\
\hline México & $\begin{array}{l}2002 \\
2012\end{array}$ & $\begin{array}{r}8,3 \\
15,4\end{array}$ & $\begin{array}{l}17,7 \\
23,4\end{array}$ & $\begin{array}{l}22,0 \\
23,1\end{array}$ & $\begin{array}{l}26,2 \\
20,2\end{array}$ & $\begin{array}{l}25,8 \\
17,9\end{array}$ & $\begin{array}{l}100,0 \\
100,0\end{array}$ \\
\hline Nicaragua & $\begin{array}{l}2001 \\
2009\end{array}$ & $\begin{array}{l}51,0 \\
59,4\end{array}$ & $\begin{array}{l}24,0 \\
23,8\end{array}$ & $\begin{array}{r}13,2 \\
9,5\end{array}$ & $\begin{array}{l}7,7 \\
4,9\end{array}$ & $\begin{array}{l}4,2 \\
2,4\end{array}$ & $\begin{array}{l}100,0 \\
100,0\end{array}$ \\
\hline Panamá & $\begin{array}{l}2002 \\
2011\end{array}$ & $\begin{array}{l}23,4 \\
23,1\end{array}$ & $\begin{array}{l}17,8 \\
18,4\end{array}$ & $\begin{array}{l}18,2 \\
19,1\end{array}$ & $\begin{array}{l}20,6 \\
20,0\end{array}$ & $\begin{array}{l}19,9 \\
19,4\end{array}$ & $\begin{array}{l}100,0 \\
100,0\end{array}$ \\
\hline Perú & $\begin{array}{l}2001 \\
2012\end{array}$ & $\begin{array}{l}29,5 \\
21,1\end{array}$ & $\begin{array}{l}24,2 \\
22,2\end{array}$ & $\begin{array}{l}21,0 \\
23,1\end{array}$ & $\begin{array}{l}15,7 \\
20,5\end{array}$ & $\begin{array}{r}9,6 \\
13,0\end{array}$ & $\begin{array}{l}100,0 \\
100,0\end{array}$ \\
\hline Paraguay & $\begin{array}{l}2001 \\
2011\end{array}$ & $\begin{array}{l}27,3 \\
32,3\end{array}$ & $\begin{array}{l}21,7 \\
22,6\end{array}$ & $\begin{array}{l}21,7 \\
19,4\end{array}$ & $\begin{array}{l}16,5 \\
14,5\end{array}$ & $\begin{array}{l}12,8 \\
11,2\end{array}$ & $\begin{array}{l}100,0 \\
100,0\end{array}$ \\
\hline República Dominicana & $\begin{array}{l}2002 \\
2012\end{array}$ & $\begin{array}{l}20,8 \\
33,3\end{array}$ & $\begin{array}{l}22,5 \\
24,0\end{array}$ & $\begin{array}{l}22,4 \\
17,2\end{array}$ & $\begin{array}{l}19,5 \\
14,6\end{array}$ & $\begin{array}{l}14,7 \\
11,0\end{array}$ & $\begin{array}{l}100,0 \\
100,0\end{array}$ \\
\hline Uruguay & $\begin{array}{l}2002 \\
2012\end{array}$ & $\begin{array}{l}3,4 \\
3,0\end{array}$ & $\begin{array}{l}12,3 \\
10,4\end{array}$ & $\begin{array}{l}20,0 \\
19,4\end{array}$ & $\begin{array}{l}29,2 \\
30,1\end{array}$ & $\begin{array}{l}35,1 \\
37,1\end{array}$ & $\begin{array}{l}100,0 \\
100,0\end{array}$ \\
\hline Venezuela (República Bolivariana de) & 2002 & 11,1 & 15,4 & 21,2 & 25,3 & 27,0 & 100,0 \\
\hline & 2012 & 6,5 & 12,7 & 20,2 & 28,1 & 32,3 & 100,0 \\
\hline
\end{tabular}

Fuente: Elaboración propia sobre la base de Banco Mundial, Indicadores del Desarrollo Mundial y datos de las encuestas de hogares de los respectivos países.

a En dólares del año 2005 expresados en paridad del poder adquisitivo (PPA). 
CUADRO A.2

América Latina (18 países): distribución de la población por quintiles del ingreso regional ${ }^{\mathrm{a}}$

(En porcentajes)

\begin{tabular}{|c|c|c|c|c|c|c|c|}
\hline & & Quintil 1 & Quintil 2 & Quintil 3 & Quintil 4 & Quintil 5 & Total \\
\hline Argentina & $\begin{array}{l}2002 \\
2012\end{array}$ & $\begin{array}{r}23,2 \\
9,6\end{array}$ & $\begin{array}{l}19,5 \\
13,4\end{array}$ & $\begin{array}{l}19,1 \\
19,9\end{array}$ & $\begin{array}{l}19,3 \\
26,1\end{array}$ & $\begin{array}{l}18,9 \\
31,0\end{array}$ & $\begin{array}{l}100,0 \\
100,0\end{array}$ \\
\hline Bolivia (Estado Plurinacional de) & $\begin{array}{l}2002 \\
2011\end{array}$ & $\begin{array}{l}38,5 \\
26,9\end{array}$ & $\begin{array}{l}21,4 \\
23,8\end{array}$ & $\begin{array}{l}15,4 \\
21,7\end{array}$ & $\begin{array}{l}13,7 \\
17,5\end{array}$ & $\begin{array}{l}10,9 \\
10,1\end{array}$ & $\begin{array}{l}100,0 \\
100,0\end{array}$ \\
\hline Brasil & $\begin{array}{l}2002 \\
2012\end{array}$ & $\begin{array}{l}18,4 \\
13,2\end{array}$ & $\begin{array}{l}17,0 \\
14,5\end{array}$ & $\begin{array}{l}18,0 \\
17,6\end{array}$ & $\begin{array}{l}20,8 \\
23,7\end{array}$ & $\begin{array}{l}25,7 \\
31,1\end{array}$ & $\begin{array}{l}100,0 \\
100,0\end{array}$ \\
\hline Chile & $\begin{array}{l}2000 \\
2011\end{array}$ & $\begin{array}{l}6,2 \\
6,6\end{array}$ & $\begin{array}{l}11,7 \\
13,5\end{array}$ & $\begin{array}{l}18,8 \\
21,9\end{array}$ & $\begin{array}{l}27,3 \\
27,7\end{array}$ & $\begin{array}{l}36,0 \\
30,3\end{array}$ & $\begin{array}{l}100,0 \\
100,0\end{array}$ \\
\hline Colombia & $\begin{array}{l}2002 \\
2012\end{array}$ & $\begin{array}{l}23,7 \\
24,3\end{array}$ & $\begin{array}{l}23,0 \\
22,2\end{array}$ & $\begin{array}{l}20,9 \\
20,6\end{array}$ & $\begin{array}{l}17,9 \\
18,1\end{array}$ & $\begin{array}{l}14,5 \\
14,7\end{array}$ & $\begin{array}{l}100,0 \\
100,0\end{array}$ \\
\hline Costa Rica & $\begin{array}{l}2002 \\
2012\end{array}$ & $\begin{array}{r}8,2 \\
12,1\end{array}$ & $\begin{array}{l}10,0 \\
16,2\end{array}$ & $\begin{array}{l}17,3 \\
21,3\end{array}$ & $\begin{array}{l}27,7 \\
23,3\end{array}$ & $\begin{array}{l}36,8 \\
27,0\end{array}$ & $\begin{array}{l}100,0 \\
100,0\end{array}$ \\
\hline Ecuador & $\begin{array}{l}2002 \\
2012\end{array}$ & $\begin{array}{l}22,4 \\
22,3\end{array}$ & $\begin{array}{l}23,4 \\
25,2\end{array}$ & $\begin{array}{l}22,7 \\
23,8\end{array}$ & $\begin{array}{l}18,5 \\
18,1\end{array}$ & $\begin{array}{l}13,0 \\
10,6\end{array}$ & $\begin{array}{l}100,0 \\
100,0\end{array}$ \\
\hline El Salvador & $\begin{array}{l}2001 \\
2012\end{array}$ & $\begin{array}{l}24,6 \\
33,2\end{array}$ & $\begin{array}{l}21,4 \\
29,9\end{array}$ & $\begin{array}{l}20,9 \\
20,4\end{array}$ & $\begin{array}{l}19,7 \\
11,6\end{array}$ & $\begin{array}{r}13,4 \\
4,9\end{array}$ & $\begin{array}{l}100,0 \\
100,0\end{array}$ \\
\hline Guatemala & $\begin{array}{l}2002 \\
2006\end{array}$ & $\begin{array}{l}30,6 \\
44,9\end{array}$ & $\begin{array}{l}26,5 \\
23,7\end{array}$ & $\begin{array}{l}17,8 \\
14,4\end{array}$ & $\begin{array}{r}14,5 \\
9,9\end{array}$ & $\begin{array}{r}10,6 \\
7,0\end{array}$ & $\begin{array}{l}100,0 \\
100,0\end{array}$ \\
\hline Honduras & $\begin{array}{l}2002 \\
2010\end{array}$ & $\begin{array}{l}55,2 \\
58,8\end{array}$ & $\begin{array}{l}20,0 \\
18,3\end{array}$ & $\begin{array}{l}12,3 \\
11,7\end{array}$ & $\begin{array}{l}7,7 \\
6,9\end{array}$ & $\begin{array}{l}4,8 \\
4,2\end{array}$ & $\begin{array}{l}100,0 \\
100,0\end{array}$ \\
\hline México & $\begin{array}{l}2002 \\
2012\end{array}$ & $\begin{array}{l}13,0 \\
25,7\end{array}$ & $\begin{array}{l}22,8 \\
28,0\end{array}$ & $\begin{array}{l}23,9 \\
22,3\end{array}$ & $\begin{array}{l}21,9 \\
14,1\end{array}$ & $\begin{array}{r}18,3 \\
9,9\end{array}$ & $\begin{array}{l}100,0 \\
100,0\end{array}$ \\
\hline Nicaragua & $\begin{array}{l}2001 \\
2009\end{array}$ & $\begin{array}{l}43,5 \\
46,8\end{array}$ & $\begin{array}{l}23,6 \\
25,9\end{array}$ & $\begin{array}{l}15,8 \\
15,5\end{array}$ & $\begin{array}{r}11,0 \\
8,0\end{array}$ & $\begin{array}{l}6,2 \\
3,8\end{array}$ & $\begin{array}{l}100,0 \\
100,0\end{array}$ \\
\hline Panamá & $\begin{array}{l}2002 \\
2011\end{array}$ & $\begin{array}{l}19,0 \\
18,9\end{array}$ & $\begin{array}{l}15,5 \\
16,7\end{array}$ & $\begin{array}{l}18,0 \\
19,9\end{array}$ & $\begin{array}{l}22,1 \\
22,9\end{array}$ & $\begin{array}{l}25,4 \\
21,6\end{array}$ & $\begin{array}{l}100,0 \\
100,0\end{array}$ \\
\hline Perú & $\begin{array}{l}2001 \\
2012\end{array}$ & $\begin{array}{l}27,3 \\
18,0\end{array}$ & $\begin{array}{l}24,1 \\
21,3\end{array}$ & $\begin{array}{l}21,9 \\
24,7\end{array}$ & $\begin{array}{l}16,3 \\
22,7\end{array}$ & $\begin{array}{l}10,4 \\
13,3\end{array}$ & $\begin{array}{l}100,0 \\
100,0\end{array}$ \\
\hline República Dominicana & $\begin{array}{l}2002 \\
2012\end{array}$ & $\begin{array}{l}22,2 \\
32,6\end{array}$ & $\begin{array}{l}21,2 \\
21,5\end{array}$ & $\begin{array}{l}21,2 \\
17,7\end{array}$ & $\begin{array}{l}20,0 \\
16,3\end{array}$ & $\begin{array}{l}15,4 \\
11,9\end{array}$ & $\begin{array}{l}100,0 \\
100,0\end{array}$ \\
\hline Uruguay & $\begin{array}{l}2002 \\
2012\end{array}$ & $\begin{array}{l}3,4 \\
3,4\end{array}$ & $\begin{array}{r}10,1 \\
8,9\end{array}$ & $\begin{array}{l}17,6 \\
18,3\end{array}$ & $\begin{array}{l}29,8 \\
32,6\end{array}$ & $\begin{array}{l}39,1 \\
36,9\end{array}$ & $\begin{array}{l}100,0 \\
100,0\end{array}$ \\
\hline Venezuela (República Bolivariana de) & $\begin{array}{l}2002 \\
2012\end{array}$ & $\begin{array}{l}23,7 \\
16,1\end{array}$ & $\begin{array}{l}21,7 \\
22,3\end{array}$ & $\begin{array}{l}20,8 \\
24,6\end{array}$ & $\begin{array}{l}19,3 \\
24,1\end{array}$ & $\begin{array}{l}14,5 \\
13,0\end{array}$ & $\begin{array}{l}100,0 \\
100,0\end{array}$ \\
\hline
\end{tabular}

Fuente: Elaboración propia sobre la base de datos de las encuestas de hogares de los respectivos países.

a Ingreso relativo a la línea de pobreza (LP). 


\begin{tabular}{|c|c|c|}
\hline Grupo & País & $\begin{array}{l}\text { Variación porcentual del ingreso per cápita } \\
\text { expresado en } \mathrm{PPA}^{\mathrm{a}}, 2002-2011\end{array}$ \\
\hline 1 & El Salvador & -10 \\
\hline 1 & República Dominicana & -2 \\
\hline 1 & Ecuador & 0 \\
\hline 1 & México & 3 \\
\hline 2 & Guatemala & 6 \\
\hline 2 & Honduras & 7 \\
\hline 2 & Nicaragua & 7 \\
\hline 3 & Panamá & 11 \\
\hline 3 & Chile & 16 \\
\hline 4 & Perú & 31 \\
\hline 4 & Costa Rica & 32 \\
\hline 4 & Brasil & 32 \\
\hline 4 & Bolivia (Estado Plurinacional de) & 33 \\
\hline 4 & Colombia & 46 \\
\hline 5 & Venezuela (República Bolivariana de) & 52 \\
\hline 5 & Uruguay & 53 \\
\hline 5 & Paraguay & 53 \\
\hline 5 & Argentina & 76 \\
\hline
\end{tabular}

Fuente: Elaboración propia sobre la base de Banco Mundial, Indicadores del Desarrollo Mundial y datos de las encuestas de hogares de los respectivos países.

a Ingreso per cápita expresado en paridad del poder adquisitivo (PPA).

América Latina (18 países): contribución a la desigualdad intragrupal, 2002 y 2012

\begin{tabular}{|c|c|c|c|c|c|c|}
\hline & \multicolumn{3}{|c|}{2002} & \multicolumn{3}{|c|}{2012} \\
\hline & $\begin{array}{l}\text { Índice } \\
\text { de Theil }\end{array}$ & $\begin{array}{c}\text { Participación } \\
\text { porcentual } \\
\text { en el ingreso }\end{array}$ & $\begin{array}{l}\text { Contribución } \\
\text { porcentual a } \\
\text { la desigualdad } \\
\text { intragrupal }\end{array}$ & $\begin{array}{l}\text { Índice } \\
\text { de Theil }\end{array}$ & $\begin{array}{c}\text { Participación } \\
\text { porcentual } \\
\text { en el ingreso }\end{array}$ & $\begin{array}{c}\text { Contribución } \\
\text { porcentual a } \\
\text { la desigualdad } \\
\text { intragrupal }\end{array}$ \\
\hline Argentina & 0,487 & 5 & 4 & 0,322 & 6 & 4 \\
\hline Bolivia (Estado Plurinacional de) & 0,742 & 1 & 1 & 0,391 & 1 & 1 \\
\hline Brasil & 0,735 & 41 & 49 & 0,614 & 44 & 52 \\
\hline Chile & 0,570 & 4 & 4 & 0,450 & 4 & 3 \\
\hline Colombia & 0,660 & 6 & 7 & 0,570 & 7 & 8 \\
\hline Costa Rica & 0,465 & 1 & 1 & 0,501 & 1 & 1 \\
\hline Ecuador & 0,565 & 2 & 2 & 0,434 & 2 & 2 \\
\hline El Salvador & 0,505 & 1 & 1 & 0,368 & 1 & 0 \\
\hline Guatemala & 0,596 & 2 & 2 & 0,680 & 1 & 1 \\
\hline Honduras & 0,768 & 1 & 1 & 0,617 & 1 & 1 \\
\hline México & 0,486 & 23 & 18 & 0,469 & 20 & 18 \\
\hline Nicaragua & 0,824 & 1 & 1 & 0,440 & 0 & 0 \\
\hline Panamá & 0,612 & 1 & 1 & 0,529 & 1 & 1 \\
\hline Perú & 0,619 & 4 & 4 & 0,404 & 5 & 4 \\
\hline Paraguay & 0,655 & 1 & 1 & 0,588 & 1 & 1 \\
\hline República Dominicana & 0,533 & 2 & 1 & 0,420 & 1 & 1 \\
\hline Uruguay & 0,357 & 1 & 1 & 0,247 & 1 & 0 \\
\hline Venezuela (República Bolivariana de) & 0,400 & 3 & 2 & 0,273 & 4 & 2 \\
\hline
\end{tabular}

Fuente: Elaboración propia sobre la base de Banco Mundial, Indicadores del Desarrollo Mundial y datos de las encuestas de hogares de los respectivos países. 


\section{Bibliografía}

Alesina, A. y R. Perotti (1996), "Income distribution, political instability and investment", European Economic Review, vol. 40, $\mathrm{N}^{\circ}$ 6, Amsterdam, Elsevier.

Alesina, A. y D. Rodrik (1994), "Distributive politics and economic growth", The Quarterly Journal of Economics, vol. 109, $\mathrm{N}^{\circ} 2$, Oxford University Press.

Anand, S. y P. Segal (2015), "The global distribution of income", Handbook of Income Distribution, vol. 2, Amsterdam, Elsevier. (2008), "What do we know about global income inequality?", Journal of Economic Literature, vol. 46, $\mathrm{N}^{\circ}$ 1, Nashville, Tennessee, American Economic Association.

Alvaredo, F. y L. Gasparini (2015), "Recent trends in inequality and poverty in developing countries", Handbook of Income Distribution, A. Atkinson y F. Bourguignon (eds.), vol. 2, Amsterdam, Elsevier.

Atkinson, A. (2015), Inequality: What Can Be Done?, Cambridge, Massachusetts, Harvard University Press.

Azevedo, J. y otros (2013), "Fifteen years of inequality in Latin America: how have labor markets helped?", Policy Research Working Papers, $\mathrm{N}^{\circ}$ 6384, Washigton, D.C., Banco Mundial.

Barro, R. (2000), "Inequality and growth in a panel of countries", Journal of Economic Growth, vol. 5, $\mathrm{N}^{\circ} 1$, Springer.

Berry, A., F. Bourguignon y C. Morrison (1983), "The level of world inequality: how much can one say?", Review of Income and Wealth, vol. 29, $\mathrm{N}^{\circ} 3$, Wiley.

Bourguignon, F. y C. Morrison (2002), "Inequality among world citizens: 1820-1992", American Economic Review, vol. 92, $\mathrm{N}^{\circ} 4$, Nashville, Tennessee, American Economic Association.

CEPAL (Comisión Económica para América Latina y el Caribe) (2014), Pactos para la igualdad: hacia un futuro sostenible (LC/G.2586(SES.35/3)), Santiago.

(2013), Panorama Social de América Latina 2013 (LC/G.2580), Santiago.

(2012), Panorama Social de América Latina 2010 (LC/ G.2514-P), Santiago.

Chen, S. y M. Ravallion (2010), "The developing world is poorer than we thought, but no less successful in the fight against poverty", Quarterly Journal of Economics, vol. 125, $\mathrm{N}^{\circ} 4$, Oxford University Press.

Cornia, G.A. (2010), "Income distribution under Latin America's new left regimes", Journal of Human Development and Capabilities, vol. 11, $\mathrm{N}^{\circ} 1$, Taylor \& Francis.

De la Torre, A., J. Messina y S. Pienknagura (2012), The Labor Market Story behind Latin America's Transformation, Washington, D.C., Banco Mundial.

Feldstein, M. (1999), "Reducing poverty not inequality", The Public Interest, $\mathrm{N}^{\circ} 137$.

Gasparini, L. y otros (2012), "Educational upgrading and returns to skills in Latin America. Evidence from a supply-demand framework, 1990-2010", CEDLAS Working Papers, $\mathrm{N}^{\circ} 127$, La Plata, Centro de Estudios Distributivos, Laborales y Sociales (CEDLAS).
(2008), "Spatial welfare disparities in Latin America and the Caribbean", La Plata, Centro de Estudios Distributivos, Laborales y Sociales (CEDLAS).

Gasparini, L. y P. Gluzmann (2012), "Estimating income poverty and inequality from Gallup World Poll: the case of Latin America and the Caribbean", Journal of Income Distribution, vol. $21, \mathrm{~N}^{\circ} 1$.

Lakner, C. y B. Milanovic (2013), "Global income distribution: from the fall of the Berlin Wall to the Great Recession", Policy Research Working Papers, $\mathrm{N}^{\circ}$ 6719, Washington, D.C., Banco Mundial.

López-Calva, L. y N. Lustig (2010), Declining Inequality in Latin America. A Decade of Progress?, Washington, D.C., Brookings Institution Press.

Milanovic, B. (2015), "Global inequality of opportunity: how much of our income is determined by where we live", Review of Economics and Statistics, vol. 97, $\mathrm{N}^{\circ} 2$, Cambridge, Massachusetts, The MIT Press.

(2012), "Global inequality recalculated and updated: the effect of new PPP estimates on global inequality and 2005 estimates", Journal of Economic Inequality, vol. 10, $\mathrm{N}^{\circ} 1$, Springer.

(2007), "Why we all care about inequality (but some of us are loathe to admit it)", Challenge, vol. 50, $\mathrm{N}^{\circ} 6$, Taylor $\&$ Francis.

(2005), La era de las desigualdades. Dimensiones de la desigualdad internacional y global, Madrid, Editorial Sistema.

Niño-Zarazúa, M., L. Roope y F. Tarp (2014), "Global interpersonal inequality: trends and measurement", WIDER Working Paper, $\mathrm{N}^{\circ}$ 2014/004, Instituto Mundial de Investigaciones de Economía del Desarrollo (UNU-WIDER).

Persson, T. y G. Tabellini (1994), "Is inequality harmful for growth?", American Economic Review, vol. 84, N ${ }^{\circ}$ 3, Nashville, Tennessee, American Economic Association.

Ravallion, M. y S. Chen (2003), "Measuring pro-poor growth", Economic Letters, vol. 78, $\mathrm{N}^{\circ}$ 1, Amsterdam, Elsevier.

Ravallion, M., S. Chen y P. Sangraula (2009), "Dollar a day revisited", World Bank Economic Review, vol. 23, N 2, Washington, D.C., Banco Mundial.

Roberts, K. (2014), "The politics of inequality and redistribution in Latin America's post-adjustment era", Falling Inequality in Latin America. Policy Changes and Lessons, G.A. Cornia (ed.), Oxford University Press.

Roemer, J. (1998), Equality of Opportunity, Cambridge, Massachusetts, Harvard University Press.

Sala-i-Martin, X. (2006), "The world distribution of income: falling poverty and ... convergence, period", Quarterly Journal of Economics, vol. 121, $\mathrm{N}^{\circ}$ 2, Oxford University Press.

Schultz, T.P. (1998), "Inequality in the distribution of personal income in the world: how it is changing and why", Journal of Population Economics, vol. 11, $\mathrm{N}^{\circ}$ 3, Springer. 